\title{
Do high-income households 'label' family cash benefits? Evidence on family expenditures from Australia
}

\author{
Gabriele Mari* \\ Renske Keizer \\ Erasmus University Rotterdam \\ Erasmus University Rotterdam
}

This is a postprint. A slightly amended version of the article has been published open access here: https://doi.org/10.1016/j.ssresearch.2022.102830.

Replication materials for this paper can be found at https://osf.io/v5qc2/.

\begin{abstract}
This study examines family expenditures and how they respond to the provision of family cash transfers, particularly among higher-income families. Naming cash benefits with explicit reference to 'families' or 'children' can nudge households into labelling the extra cash for financial investments in children. Labelling has mainly been assessed among lower-income families. Yet if also higher-income families engage in labelling, there could be unintended consequences on the often stark disparities in child-related investments across the socio-economic divide.

Drawing on 2006-2019 data from Household, Income, and Labour Dynamics in Australia (HILDA), the study relies on reforms to Australia's Family Tax Benefit to 'reveal' expenditure responses among higher-income families via an instrumented difference-in-differences design. Higher-income households seem to earmark a family cash transfer for children's clothing but not for children's education fees, while they also assign money to adult clothing. Lower-income households, differently, seem to engage in more clear-cut, child-oriented labelling, at the expense of adult-assignable goods. Family cash transfers can nudge households into spending more money on their children across the socioeconomic divide, but not necessarily homogeneously so. Providing more well-off families with modest transfers might thus have limited perverse effects on inequality in family expenditures.
\end{abstract}

Keywords: Family cash transfers - Parental investments - High-income families - Socioeconomic inequalities - Labelling

*E-mail: mari@essb.eur.nl. This study was supported by a grant from the Netherlands Organization for Scientific Research (NWO MaGW VIDI grant no. 452-17-005 to R.K.) and by a grant from the European Research Council (ERC StG grant no. 757210 to R.K.). Data in this paper come from the Household, Income and Labour Dynamics in Australia (HILDA) survey (Department of Social Services and Melbourne Institute of Applied Economic and Social Research, 2021), General Release 19, accessed via the Australian Data Archive (ADA). The authors wish to thank Mariana Amorim and Roger Wilkins for feedback and suggestions. The content of this paper is the sole responsibility of the authors. 
Worldwide, households receive cash benefits that are meant to help with the economic costs of raising children. But do parents earmark such cash benefits for investments in children, as intended by lawmakers? According to standard microeconomic principles, income is fungible, meaning that an extra dollar from family cash benefits will be spent or saved just like an extra dollar from any other source. This assumption, long criticised within sociology (e.g. Bennett, 2013; Zelizer, 2017), is irreconcilable with extensive evidence that income from different sources is also spent or saved differently. In particular, households seem to disproportionately assign income from family cash benefits to child goods, clothing in particular, and child-oriented savings (e.g. Kooreman, 2000; Hener, 2017; Lyssiotou, 2018) - the result of a 'labelling effect' in line with behavioural theories of mental accounting (e.g. Thaler, 1985, 1999; Antonides et al., 2011).

Understanding whether fungibility or labelling underlies the use of cash transfers can help design family cash benefits, especially in light of well-established socioeconomic gaps in parental (monetary) investments in children (Kornrich \& Furstenberg, 2013; Duncan et al., 2017; Schneider et al., 2018; Hastings \& Schneider, 2021; Amorim, 2021). Labelling has been primarily assessed among low-income households, who have often been the target of policy intervention. Universal family cash benefits abound, however, and little is known about families receiving cash benefits higher up in the income distribution (for an exception, Raschke, 2016). More well-off households may feel less pressure to keep expenditures in check via labelling (Antonides et al., 2011). At the same time, affluent households might treat cash benefits as a windfall and be more inclined to spend the money right away, perhaps investing (even more) in their children (cf. Kueng, 2018; Amorim, 2021). Yet if a labelling effect encourages both lower and higherincome families to spend more on child-related goods, family cash benefits might not help mitigate the often stark socioeconomic gap in child-related expenditures. Further, disparities might be even magnified to the extent that higher-income households disproportionately purchase goods, activities, and services that enrich children's human capital (Lareau, 2003; Bodovski \& Farkas, 2008; Cheadle \& Amato, 2011).

Hence, we investigate the occurrence of labelling and its implications for inequality in 
family expenditures and policy, focusing on higher-income families in Australia. Drawing from cross-country studies, expectations on parental investments across the socioeconomic divide are unclear for Australia. The country combines generous family cash transfers that have been associated with smaller socioeconomic gaps in expenditure (Jackson \& Schneider, 2021), with high income inequality - at least pre-transfers (see, e.g., Gornick \& Smeeding, 2018) - which has been correlated with wider gaps instead (Schneider et al., 2018).

Recent reforms of Family Tax Benefit, the main family cash transfer in Australia (Apps \& Rees, 2010; Ribar, 2017), have withdrawn part of the benefit from more well-off households, first in 2008 and later in 2015. By relying on an instrumented difference-indifferences approach, we use these reforms to analyse expenditure responses to family cash transfers among Australian households. We ask if, counterfactually, higherincome families would have kept labelling family benefits for child-assignable goods. Using data from the Household, Income and Labour Dynamics in Australia (HILDA) survey, we can infer labelling by comparing child-related expenditures to those for household and adult-related goods. We tap onto some child goods in line with prior research (i.e. children's clothing), as well as more seldom examined education expenditures. These direct investments in children's human capital are of particular importance in the Australian context, where the proportion of secondary school students in private institutions is higher than the OECD average and has been growing faster than any other comparable OECD country in the last decades (Lye \& Hirschberg, 2017). Finally, we will benchmark labelling effects among high-income families to the spending behaviour of families on lower incomes receiving the same cash benefit, to have a sense of the contribution transfers can make to overall inequalities in expenditures.

We make two main contributions. The first adds to research on disparities in family expenditures and parental investments in children (e.g. Kornrich \& Furstenberg, 2013; Schneider et al., 2018; Amorim, 2019, 2021). The few studies that have analysed higherincome families have either focused on a few expenditure items (Raschke, 2016) or on spending responses to transfers that do not explicitly reference 'children' or 'families' (Amorim, 2021). We build on these studies and on the larger literature on labelling 
(e.g. Kooreman, 2000; Hener, 2017; Thaler, 1985) to show whether and how family cash transfers can nudge higher-income families into more child-related spending. We examine, in addition, the consequences of such spending responses for inequalities in child-related investments. Related, our second contribution is to inform scholarly and policy debates on the design of such transfers. When it comes to family expenditures, debates have concentrated on lower-income families. The behaviour of higher-income families has been left largely unquestioned, even though well-off families are often beneficiaries of transfers too. Oft-cited arguments for more universal transfers centre on avoiding high marginal taxes that can discourage paid work, easing administrative burdens, minimising stigma around uptake, and building large political coalitions in support of cash assistance (e.g. Atkinson, 2015:209-21; Apps \& Rees, 2010; Shaefer et al., 2018). Evidence on labelling could further help adjudicate between including or excluding higher-income families with children from cash assistance, depending on how the extra cash is used.

\section{Previous evidence}

Previous studies have investigated labelling effects in two ways, either by comparing households' marginal propensity to consume (MPC) one dollar from family cash benefits against one dollar from any other source or by examining interventions that may have encouraged labelling in a 'treated' vis-à-vis a comparison group. MPC studies have typically focused on children's clothing as a child-assignable good, providing mixed evidence for labelling of family cash benefits across countries (cf. Kooreman, 2000; Edmonds, 2002; Blow et al., 2012). Only one study in the MPC strand has explicitly compared lower and higher-income families, although only in terms of food expenditures, and found a larger MPC from family cash benefits for lower-income families, in the context of Germany's universal child benefit (Raschke, 2016).

MPC studies have one main limitation. These studies leverage residual variation in benefit income, after adjusting for variables affecting payments to families similarly over time (e.g. number and age of children, two-parent or single-parent family, etc.). The logic is that residual variation in income from cash benefits might then be attributed to exogenous policy changes over time (e.g. Kooreman, 2000), although the latter are not 
explicitly modelled. Further, regression adjustment may not single out exogenous variation in the other income variable, i.e. disposable income from sources other than the transfer in question. In response, MPC research has often resorted to an instrumentalvariable approach. The use of multiple and disparate instruments for disposable income (cf. Kooreman, 2000; Edmonds, 2002; Raschke, 2016), though, may obfuscate which source of income variation is used within each study and hinder comparability of estimates across studies. Besides, changes in family cash benefits may themselves affect disposable income from other sources (or instruments thereof, e.g. Edmonds, 2002), by altering work incentives and earnings (e.g. Heckman \& Mosso, 2014). In short, studies in this stream might be better poised to retrieve the MPC out of cash transfers, due to the frequency of reforms thereof, as opposed to the MPC out of all other sources of income, as it is harder to isolate exogenous variation in "all other" family income.

Alternatively then, studies have investigated interventions encouraging the labelling of cash benefits, avoiding problematic comparisons of the MPC across income sources. Some have relied on policy reforms boosting family cash benefits differentially across families, depending on household income, household composition, and area of residence (Gregg et al., 2006; Hener, 2017; Lyssiotou, 2018; Lenhart, 2019; Jones et al., 2019). One randomised control trial combined an unconditional cash transfer with targeted messaging to elicit parental investments in children's education (Benhassine et al., 2015). Findings from all these evaluations have been consistent with labelling effects, manifesting in more child-assignable spending (children's clothing and, in fewer studies, education), more spending on essentials like food and transportation (Jones et al., 2019), and less spending on adult goods like cigarettes and alcohol. Whilst more unambiguous than MPC studies, this latter strand of research may still have the drawback of mixing up labelling with pure income effects on expenditure. None of the intervention-based studies, further, have explicitly examined labelling among higherincome families and rather concentrated on interventions that primarily affected lowerincome beneficiaries (Gregg et al., 2006; Benhassine et al., 2015; Jones et al., 2019). Hence, we attempt to combine the best of both approaches. We estimate MPCs out of cash transfers and not other sources of income, as we only have credible exogenous 
variation for the former. Rather than inferring labelling directly from comparisons of expenditures across income sources, we infer labelling indirectly, i.e. in the presence of (larger) positive MPCs for child-related goods compared to other spending categories (Gregg et al., 2006; Hener, 2017; Jones et al., 2019; Amorim, 2021). For higher-income families, we can explicitly model spending responses to policy change. Further, we examine a setting where effects on labour supply and earnings are unlikely and put this claim to test.

\section{Family Tax Benefit and higher-income households}

We consider reforms of Family Tax Benefit (FTB, henceforth). Since its introduction in 2000, FTB has been the main family cash transfer for scope and coverage in Australia (Apps \& Rees, 2010; Ribar, 2017; Department of Social Services, 2020). Each year in the last two decades, Australia has devoted around 1\% of GDP to FTB expenditure (e.g. AUD 20.2 billion in 2015-16, Arthur, 2015), a figure similar to that of programs examined in previous studies (Kooreman, 2000; Raschke, 2016). The main program is FTB Part A and is accompanied by FTB Part B, a second component meant particularly for couples with one main income earner, single-parent families, and non-parent carers. In 2017-18, more than 1.6 million households received FTB-A and more than 1.3 million families were in receipt of FTB-B (Department of Social Services, 2020: 48). Uptake among the eligible is incomplete, but relatively large in comparative perspective ${ }^{1}$. FTB is means-tested and its receipts is further conditional on some health checks and immunisation requirements for young children. There are also no strings attached to how the money is spent, allowing us to assess labelling as a result of nudges (e.g. how the policy is named and advertised) rather than simply examine the efficacy of a spending

\footnotetext{
${ }^{1}$ We lack administrative data on take-up rates, especially broken down by family income, the focus in this study. However, we can compare eligibility for FTB as estimated within HILDA's Income Model and self-reported FTB receipt in HILDA's core questionnaire. In our analytical sample $(N=32,541)$, around $80 \%$ of eligible household-wave observations report receiving FTB. This figure is in line with take-up rates for other programs in Australia (Ko \& Moffitt, 2022), including the Parenting Payment that preceded FTB (Mood, 2006). Also in line with prior research (ibidem), we find a gradient by family income, and thus by size of the entitlement: Around $82 \%$ of household-wave observations belonging to the lower income group report receiving FTB, against $53 \%$ in the intermediate income group and $49 \%$ in the top income group. We can consider the latter two estimates to approximate take-up rates for FTB-B only, due to the ineligibility for FTB-A among higher-income families. Incomplete take-up is addressed in our sensitivity analyses and proves inconsequential for our main results.
} 
mandate (as in, e.g., a voucher program for specific expenses).

Most families receive FTB payments once every fortnight, with reconciliation and supplements available at the end of each financial year (running from 1 July to 30 June). Eligibility mainly depends on the presence of qualifying children and on income tests (see, e.g., Department of Human Services, 2019 for more details). Qualifying children for FTB-A are either aged 0-15 or 16-19 if enrolled in full-time education. For FTB-B, the definition depends on family structure, with children qualifying if under age 13 for couple families, and under 18 for single-parent ones. Current age limits are more restrictive than in the past and were put in place in July 2013 and July 2016 for FTB-A and FTB-B, respectively. These reforms affected eligibility regardless of family income. We will thus take these changes into account in sensitivity analyses, but we will not rely on these reforms for identification.

Rather, we are most concerned with changes in the means-tested nature of FTB. Means testing for FTB is solely carried out on the basis of parental income and there are no assets tests. Payments depend non-linearly on parental income (Harding et al., 2009; Department of Human Services, 2019). The maximum rate is paid to the lowest income households up until a certain income threshold. As of July 2019, annual benefits reached a maximum per-child rate of around 7,081 AUD for FTB-A and 4,500 AUD for FTB-B. For households whose pre-tax income is above the maximum rate area, taper rates kick in and reduce entitlements by either 20 or 30 cents per each dollar of parental income above selected income thresholds. For FTB-B in particular, when the secondary earner in the household reports incomes above a given threshold (5,694 AUD in 2019), payments are progressively withdrawn with a $20 \%$ taper.

Higher-income families receive lower payments due to taper rates, which make them largely ineligible for FTB-A (see also Figure 1). In addition, they have also been progressively excluded from FTB-B payments. Starting from the financial year 2008-9, Australian households lost their eligibility for FTB-B if the main or sole earner totalled more than 150,000 AUD in pre-tax annual income (Department of Human Services, 2009). The threshold was then lowered, this time to 100,000 AUD from 2015-16 onwards (Department of Human Services, 2016). These new income thresholds equated to around 2 
to 3 times median pre-tax personal income in the period. The reforms were consequential: Considering the population of families with children under age 16 in Australia, FTB-B receipt dropped from around 59\% in 2008-9 to 45.1\% in 2017-18 (Department of Families, Housing, Community Services, and Indigenous Affairs, 2011: 42; Department of Social Services, 2020: 42).

We will examine these changes to FTB-B to investigate whether higher-income families label FTB payments. A negative reform effect on expenditures in child-assignable goods, for example, would support the idea that, counterfactually, higher-income families would have kept labelling FTB-B for investments in their children. Given that higher-income families receive more meagre payments, we further expect that reforms affected expenditures via the composition of household income, but did not result in substantial net income changes that could influence expenditures, either directly or via changes in parental labour supply.

\section{Methods}

\subsection{Data and sample}

We use data from the Household, Income and Labour Dynamics in Australia (HILDA) survey (General Release 19, Department of Social Services and Melbourne Institute of Applied Economic and Social Research, 2021). Started in 2001, HILDA is an annual panel survey that follows the lives of around 17,000 Australians each year. Crucially, HILDA provides us with high-quality data on both family expenditures (Sun, 2010) as well as household income and benefit receipt (Wilkins, 2014).

We use all waves from Wave 6 to Wave 19, thus relying on expenditure measures collected via the self-completion questionnaire since Wave 6. Given that expenditure and income measures refer to the previous financial year, we cover financial years from 2005-06 to 2018-19. We aggregate data at the level of income units, defined in HILDA as "subsets of the family thought to systematically pool their income and savings" (Summerfield et al., 2020). For simplicity, although we will include all separate income units when more than one belongs to the same family/household, we will refer to sample units as families or households.

The starting sample thus consists of 147,514 household-wave observations. We keep 
only records for which we can observe children qualifying for FTB (Wilkins, 2014), using the broadest definition for the period - comprising all children aged 0-15 and 16-24 if full-time students. Because of this first restriction, we drop 109,405 householdwave observations. We also exclude observations if any adult member in the household is 60 or older (1,056 observations) to avoid tapping into income and expenditure dynamics around retirement. We drop 270 observations belonging to households where someone other than either partner was indicated as the financial decision-maker in the household. As one of our main focuses is on education fees, we make sure these are child-assignable by dropping 414 observations where the household includes an adult member (aged 25 or older) that reports education as their main activity. 1,433 observations are dropped due to missing values. This count includes 61 observations who reported a negative net income for the previous financial year. 578 observations have missing values for the age of the primary earner. Most of the remaining incomplete cases (475 out of 794) have missing values for self-reported FTB receipt. Since we only rely on this latter variable for sensitivity checks, we were able to carry out our main analyses including observations that are missing on self-reported FTB and results were unchanged. Finally, we trim the top $1 \%$ for each expenditure to limit the influence of outliers (2,395 observations, e.g., Schneider et al., 2018; Amorim, 2021).

The final sample consists of 32,541 household-wave records, nested in 6,467 households. Among them, we define three income groups in relation to reforms of FTB-B. We distinguish families in which the primary or sole earner reports an annual adjusted income 1) of less than 100,000 AUD, 2) between 100 and 150,000 AUD, and 3) of 150,000 AUD or more. Families with earners in the latter two groups are those affected by FTBB reform. Such families are in the top half of the earnings distribution in Australia ${ }^{2}$, considering that median pre-tax earnings equalled 50,861 AUD in 2017-18 (Australian

\footnotetext{
${ }^{2}$ We focus on income cutoffs dictated by FTB-B reforms, whereas previous studies have typically used groupings based on percentiles of the income distribution (e.g. p1-p25, p26-75, p76-90, p91-100, Schneider et al., 2018). There is a strong correspondence between our groupings and those of prior research. Taking the earnings distribution of primary earners in each year, around $95 \%$ of householdwave observations in our top-income group are in the p91-100 group, $87 \%$ of the intermediate group is either in the p76-90 group (74\%) or in the p91-100 group (13\%), and $94 \%$ of the bottom-income group is either in the p1-25 group (32\%) or in the p26-75 group (62\%). Our main results largely map back to these percentile-based groupings, unless noted (e.g. footnote 4; analyses by income rank are available upon request).
} 
Bureau of Statistics, 2021).

In the pooled sample, around 77\% household-wave observations belong to the bottom income group ( $n=25,084), 14 \%$ to the intermediate income group $(n=4,675)$, and $9 \%$ to the top income group $(n=2,782)$. As per Table 1 , the composition of the two groups is largely comparable when it comes to the number of children in different age bands, although households in the two higher-income groups have more children in their teens and early 20s on average. The primary earner is also older, on average, among higher-income families. These might be relevant compositional and time-varying differences, as expenditures (as well as, on the other hand, the propensity to save) may vary with both children's and parental age. Notably, only a small fraction of households are headed by a single parent in the intermediate and top income group, while around $46 \%$ of household-wave observations belong to single parents in the lowerincome group. Single parents were affected by a spate of reforms in the period (de Gendre et al., 2021). To limit the influence of concomitant reforms, we will probe our analyses to the exclusion of single-parent families from the sample.

Table 1: Sample composition by income group.

\begin{tabular}{lccc}
\hline & Below 100,00 AUD & $100-150,000$ AUD & 150,000 AUD or more \\
\cline { 2 - 4 } No. children age 0-4 & 0.58 & 0.55 & 0.55 \\
No. children age 5-12 & 0.83 & 0.80 & 0.89 \\
No. children age 13-18 & 0.42 & 0.47 & 0.48 \\
No. children age 19-24 & 0.03 & 0.06 & 0.09 \\
Age of primary earner & 38.7 & 41.9 & 43 \\
Single parent & .46 & .07 & .04 \\
\hline$n_{\text {observations }}$ & 25,084 & 4,675 & 2,782 \\
\hline
\end{tabular}

\subsection{Empirical approach: estimating MPCs via policy change}

Our approach rests on policy changes that resulted in the withdrawal of Family Tax Benefit Part B from higher-income families. These changes are portrayed in Figure 1. Throughout, we rely on estimated benefit amounts, assigned to each household via a tax-benefit simulation module known as HILDA's Income Model (Wilkins, 2014). Estimated and actual amounts may differ, especially if families do not take up their FTB entitlement; we will address this in sensitivity analyses. Figure 1 plots average estimated amounts for both FTB-A and FTB-B across households in the three income 
groups. Due to the income-tested nature of FTB, it is no surprise that families in the lower-income group collect the highest entitlements, first from FTB-A and secondly from FTB-B. Families in the two higher-income groups collect most of their entitlements from FTB-B, whilst being largely ineligible for FTB-A (around 5\% of householdwave observations in the intermediate income group are assigned a non-zero FTB-A amount by the HILDA's income model). However, after reforms targeted families in the highest-income group in 2008-09 and the second-highest income group in 2015-16, FTB-B amounts reduce to 0 .

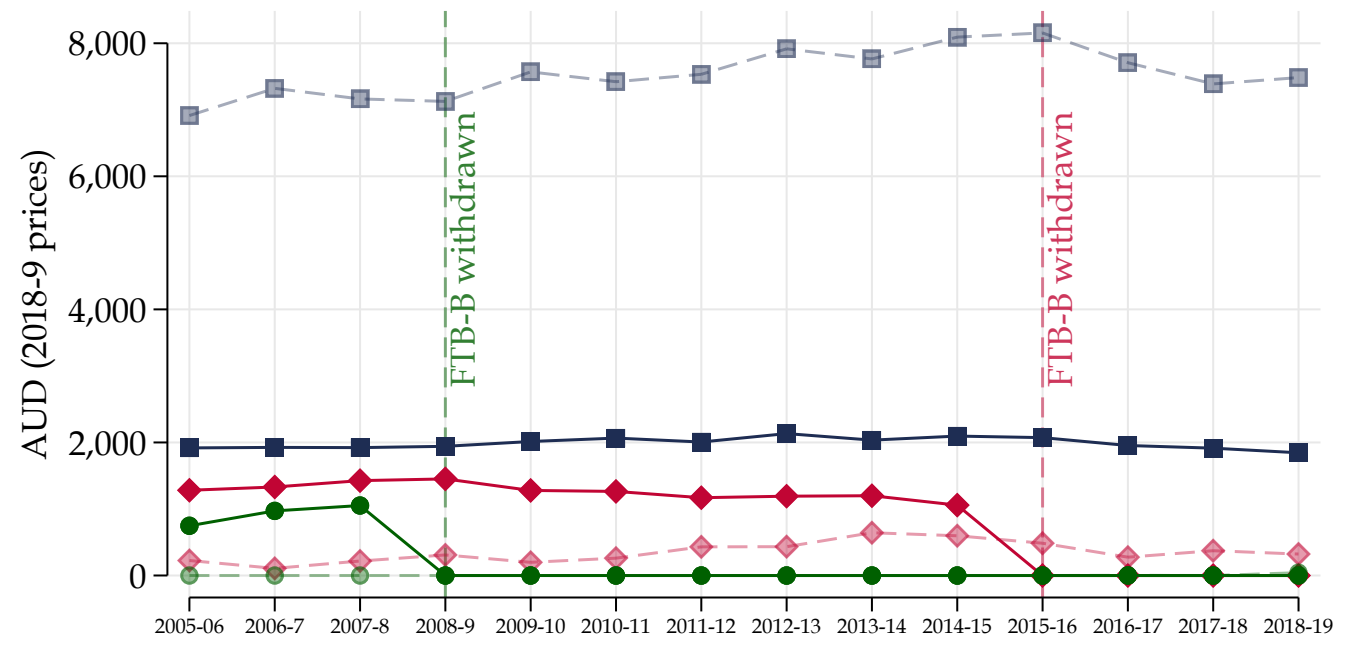

Financial year

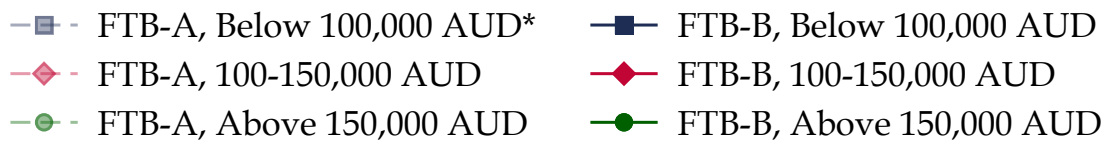

* Income bands refer to the total annual adjusted taxable income of the primary/sole earner.

Figure 1: Estimated Family Tax Benefit amounts by income band and financial year. Dashed vertical lines indicate FTB-B reforms, withdrawing payments from families in the top (green) and intermediate (red) income band.

These reductions in FTB-B amounts can be retrieved via the following linear regression model:

$$
\text { FTB- } \mathrm{B}_{h w}=c_{1}+\alpha_{1 g}+\lambda_{1 t}+\mathbf{x}_{1 \mathrm{gt}} \beta+\mathbf{z}_{1 \mathrm{hw}} \gamma+\epsilon_{h w}
$$

where $\alpha_{1 g}$ captures the effects of income-group dummies $g$ (with households with incomes below 100,000 AUD as the reference) and $\lambda_{1 t}$ stands for period dummies dis- 
tinguishing pre- and post-reform periods based on financial year $t$ (before and after 2008-09 and before and after 2015-16). The model is then saturated in that it includes all interaction terms between income-group dummies and period dummies $\left(\mathrm{x}_{1 \mathrm{gt}}\right)$. Two of those interaction terms capture "policy effects", respectively for households with incomes above 150,000 AUD after 2008-09 and households with incomes between 100,000 and 150,000 AUD after 2015-16. In practice, these are the regression counterparts of a difference-in-differences (DiD) estimand, and a causal interpretation of policy effects thus rests on the assumption of parallel outcome trends. Figure 1 provides a first reassurance that, if not for the reforms in question, trends in FTB-B amounts would have continued to evolve in parallel, staying relatively flat for all income groups.

Our interest lies in if and how family expenditures responded to the withdrawal of FTB-B. We thus take Equation 1 to be the first stage of an instrumental-variable (IV) approach (Duflo, 2001; see also Hudson et al. 2017). We rely on the two interaction terms capturing policy effects to instrument for FTB-B ${ }_{h w}$. In other words, this instrumented difference-in-differences setting imposes that reforms only affected well-off households due to the ceased provision of FTB-B. Further challenges to identification and estimation are discussed in Section 1A.

With the vector $\mathbf{z}_{\mathbf{h w}}$, we add, first, a limited set of covariates aimed at increasing precision. These are state fixed effects, a dummy for whether the observation belongs to the first or a higher-order (second or third) family/income unit in the household, a dummy for whether the relevant expenditure outcome was imputed for a given householdwave observation (in HILDA, around 15\% of expenditures are imputed, for more details see Sun, 2010), and month of interview fixed effects to account for seasonality in expenditures. This parsimonious specification maintains clarity over the sources of identification. In a second specification though, we use a more extensive set of controls to make sure that the instrument is not picking up trends in expenditures related to other time-varying factors. Also informed by previous studies (e.g. Kooreman, 2000; Hener, 2017; Schneider et al., 2018; Amorim, 2019, 2021), we include the number of children in four age bands $(0-4,5-12,13-18,19-24)$, age of the primary earner, age of the secondary earner (set to 0 in single-parent households), dummies for single- 
parent households (also distinguishing single fathers from single mothers), dummies for whether respondents reported a major improvement in their finances or a major loss with reference to the previous year, as well as state-level GDP. We allow these variables to have varying associations with the outcome by including interaction terms with the income-group dummies, a choice that also approximates the fully saturated model recommended in IV settings with covariates (Angrist \& Pischke, 2008: 177).

Table 2 provides the relevant first-stage estimates. In line with Figure 1, we estimate a reduction in FTB-B amounts by around 955-1068 AUD $(p<.001)$ for the first reform and the top-income group, and by around 1068-1115 AUD $(p<.001)$ for the second reform and the intermediate income group. Including covariates leads to a small reduction in point estimates, but once standard errors are taken into account the two specification yield statistically indistinguishable results. The effective F-statistic (Olea \& Pflueger, 2013; Andrews et al., 2019) is greater than 200 in both specifications. All in all, Table 2 reports a strong first stage, with a relevant association between the IV and transfer amounts, that also appears untainted by other observable time-varying factors.

Table 2: First-stage estimates for the effects of FTB-B reforms on FTB-B amounts (Equation 1).

\begin{tabular}{lcc}
\hline & \multicolumn{2}{c}{ FTB-B (AUD) } \\
\cline { 2 - 3 } & Coef. & Coef. \\
& $(\mathrm{SE})$ & $(\mathrm{SE})$ \\
\hline Income group $=$ Above 150,000 AUD $\times$ After 2008-09 & $-1068^{* * *}$ & $-955^{* * *}$ \\
& $(126)$ & $(121)$ \\
Income group $=100-150,000$ AUD $\times$ After 2015-16 & $-1115^{* * *}$ & $-1068^{* * *}$ \\
& $(62)$ & $(58)$ \\
\hline Other income-group/period dummies and their interaction & Yes & Yes \\
Main covariates & Yes & Yes \\
Adding time-varying controls & No & Yes \\
\hline Effective F-statistic (Olea \& Pflueger, 2013) & 202.4 & 207.3 \\
\hline \multicolumn{2}{c}{ Note: $* * * p<.001$. Sets of covariates are detailed in the main text. Standard errors are robust to } \\
heteroskedasticity and are clustered at the household level $\left(N_{\text {observations }}=32,541\right)$.
\end{tabular}

To study how these changes in transfer amounts affected expenditures, Equation 1 is estimated together with Equation 2 via two-stages least squares (2SLS). In Equation 2, we model family expenditures $Y_{h w}$ as follows: 


$$
Y_{h w}=c_{2}+\theta \text { FTB }-B_{h w}+\alpha_{2 g}+\lambda_{2 t}+\mathbf{x}_{\mathbf{2 g t}} \beta+\mathbf{z}_{\mathbf{2 h w}} \gamma+\eta_{h w}
$$

where $Y_{h w}$ is one of eight expenditure items. We selected these times in line with prior research (e.g. Kooreman, 2000; Gregg et al., 2006; Blow et al., 2012; Jones et al., 2019), with the obvious caveat that we cannot capture all spending categories, pin down substitution effects across goods, or pick up alternative avenues for labelling (saving, e.g. Hener, 2017). These are expenditures on 1) children's clothing and footwear and 2) education fees (paid to schools, universities and other education providers, including private tuition) for child-assignable goods; 3) utility bills, 4) home repairs, renovations and maintenance, and 5) groceries to tap into the home environment affecting the child; 6) adult clothing and footwear, 7) alcohol, and 8) cigarettes and tobacco for adult-assignable goods. All expenditures amounts are measured annually, except for groceries (monthly). As with all other monetary amounts in the analysis, all expenditure amounts are adjusted by taking the average of the quarterly Consumer Price Index in each financial year, and expressed in 2018-19 prices. Further, we examine per-capita and equivalised expenditures (Gregg et al., 2006; Raschke, 2016), meaning that expenditures on child goods are divided by the number of dependent children aged 0-24 in the household; bills, housing, and grocery expenditures are deflated by the standard OECD equivalence scale (i.e. assigning a weight of 0.67 to the first adult, 0.33 to all other persons in the household aged 14 or over, and 0.20 to each child under 14); adult-assignable expenditures are divided by the number of adults in the household. The key coefficient of interest is $\theta$, expressing the shift in expenditures corresponding to a 1 AUD change in FTB-B, as predicted by Equation 1. This is our estimate of the marginal propensity to consume (MPC) family cash benefits among households with higher incomes. We thus explicitly model expenditure responses to policy change. Labelling is inferred from whether we can detect the largest (positive) MPC for childrelated goods. In addition, we provide additional analyses that test whether reforms altered labour supply and earnings, to make sure that spending responses can only be ascribed to the withdrawal of FTB-B - and thus, the labelling thereof - and not to changing income inflows from paid work. 
Equation 2 is then similar to Equation 1 and includes income-group and period dummies, as well as all interaction terms between them except for the two capturing policy effects that are used as instruments in the first stage. We run models both with a parsimonious set of covariates and with a more extensive set. Throughout, standard errors are robust to arbitrary heteroskedasticity (as the variability of expenditures likely increases with household income) and are clustered at the longitudinal household level (to account for serial correlation across multiple observations per household).

\subsection{Benchmarking exercise}

In the last step of our main analyses, we conduct a "benchmarking" exercise. We ask not just whether higher-income families engage in labelling, but also if they do so at a higher rate than lower-income families. Whilst we can only approximate causal estimates for higher-income families, due to the selective nature of policy changes, we will provide "naïve" estimates of the MPC for families in the lower-income group, via the following linear model:

$$
Y_{h w}=\alpha+\beta \text { FTB-B }_{h w}+\mathbf{z}_{\mathbf{h w}} \gamma+\eta_{h w}
$$

where $Y_{h w}$ is again one of eight expenditure items. The parameter of interest is $\beta$, providing the MPC from Family Tax Benefit Pat B for each expenditure. We call it "naïve" as $\beta$ does not necessarily approximate a causal quantity. Nevertheless, it provides a robust association, by relying on residual variation in FTB-B when accounting for our most extensive set of controls - i.e. number of children in four age bands (0-4, 5-12, $13-18,19-24$ ), age of the primary earner, age of the secondary earner (set to 0 in singleparent households), dummies for single-father and single-mother households, dummies for whether respondents reported a major improvement in their finances or a major loss with reference to the previous year, state-level GDP, state and month of interview fixed effects, an indicator for multiple family units within the household and one for whether the expenditure outcome was imputed. We further augment this model by including financial year fixed effects, as well as adjusting flexibly for families' permanent income (taking the log of average net income for each household in the sample) 
and FTB-A amounts (five dummies based on quintiles), to make sure that we are not simply capturing the fact that lower-income families spend less on each item due to lower resources.

The resulting estimates provide benchmark associations between one dollar from FTBB and family expenditures for lower-income families. Comparing IV estimates for higherincome families to OLS estimates for lower-income families can suggest whether and how labelling effects dictated by FTB-B were contributing to socio-economic inequalities in expenditures. To reiterate, the OLS strategy does not provide strong grounds for causal claims. Hence, we will also estimate MPCs under Equation $3^{3}$ for the intermediate and top income groups. Finding similar OLS and IV estimates among higherincome families may lend more credibility to our OLS estimates for lower-income families and also provide a fairer and fuller test of labelling effects across the socio-economic divide.

\section{Findings}

\subsection{Descriptive results}

We start by examining family expenditures across income groups before FTB-B reform. Figure 2 plots expenditures in terms of average amounts (bars) and in proportion to net income (diamonds), pooling data from pre-reform financial years (2005-06/2007-08).

\footnotetext{
${ }^{3}$ Families in higher-income groups are de facto ineligible for FTB-A. Hence, we only adjust OLS estimates for quintiles of FTB-A among lower-income families. Also in contrast with Equation 3 for lowerincome families, we refrain from adjusting for financial year dummies in our models for higher-income families, in line with Equation 1 and 2. As higher-income families lose eligibility for FTB-B over time due to reforms, adjusting for financial year would eliminate meaningful variance in our "treatment" in Equation 3, i.e. FTB-B amounts.
} 

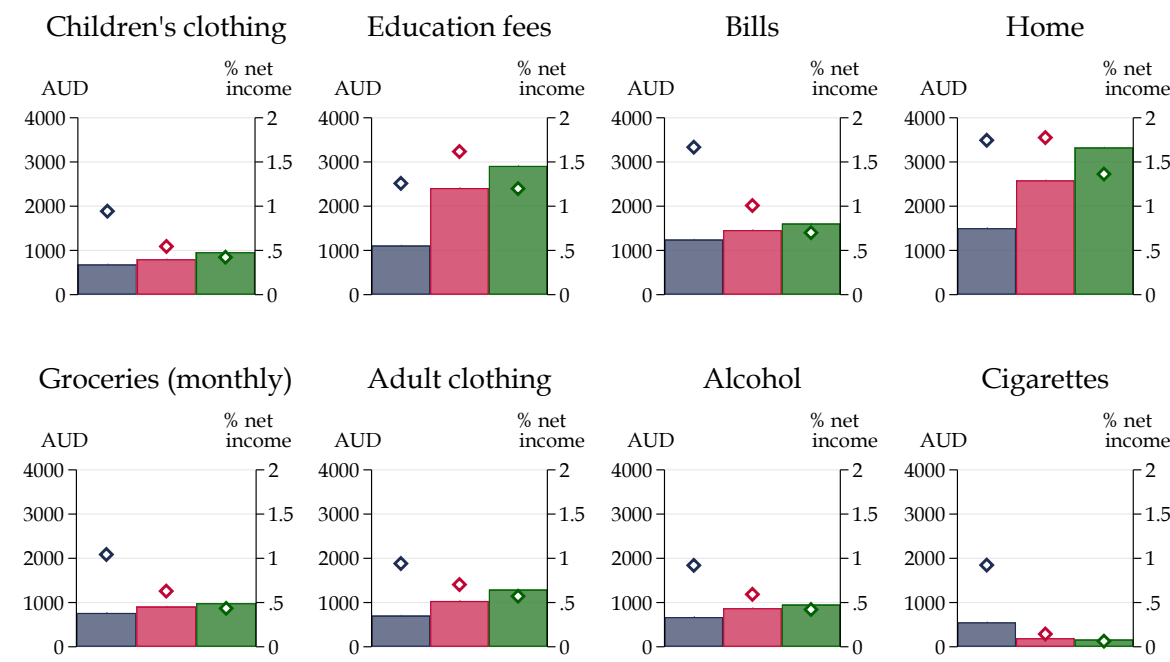

Below 100,000 AUD

100-150,000 AUD

Above 150,000 AUD

Note: bars are for average amounts in AUD (left $y$-axis), diamonds are for shares of net income (right $y$-axis). Figures refer to pooled data from pre-reform financial years (2005-06/2007-08).

Figure 2: Family expenditures by item and income band. Expenditures are expressed in average (annual, except for groceries) amounts in 2018-19 prices and as a share of net annual income. Amounts are expressed per child (children's clothing and education fees), equivalised (bills, home, groceries), and per adult (adult clothing, cigarettes, alcohol).

More well-off families spend more on all items except for cigarettes. For the first childrelated good, children's clothing, higher-income families spend an average of 960 AUD, followed by the second high-income group with around 800 AUD, and the lowest income group with 682 AUD. The gradient is even starker for education fees and home repairs and renovations. Focusing on the former, Australian families in the higher-income group spend an annual average of around 2,913 AUD per child, against 2,410 AUD in the intermediate group, and 1,109 in the lower-income group. Proportional to net income, however, education expenditures are more similar. Spending in the lowest and highest-income group is equivalent to around $1.2 \%$ of their respective net income, and to $1.6 \%$ in the $100-150,000$ AUD income bracket. In proportion to disposable income, nonetheless, lower-income families spend relatively more than their well-off counterparts on children's clothing, bills, home expenses, groceries, adult clothing, alcohol, and cigarettes. 


\subsection{Policy changes and labelling}

Reforms withdrawing FTB-B might have reduced spending on children's clothing and children's education among high-income families if part of such spending was due to the labelling of family cash transfers. To assess this, we turn to IV estimates in Figure 3. Following from the first stage displayed in Table 2, estimates refer to the marginal propensity to consume one dollar coming from FTB-B. A positive (negative) MPC suggests that, in the absence of reforms, a certain per-dollar amount out of the transfer would have continued to be assigned to (withheld from) a given expenditure.

In line with labelling, we find a positive MPC for children's clothing, of around 0.058 ( $p$ $=.001)$ or $5.8 \%$ per dollar. The point estimate reduces to $4.9 \%(p=.005)$ when adding more extensive controls, but remains statistically indistinguishable from its counterpart in the first specification. A back-of-the-envelope calculation implies that, given an average withdrawal of around 1,000 AUD among higher-income families per effect of the reforms (Table 2), expenditure for clothing reduced by 49-58 AUD per child.

Differently, we cannot detect a positive MPC for education fees, as one would have expected under labelling $(\mathrm{MPC}=-3.9 \%, p=.738$ in the more extensive specification). We find little evidence, in addition, of substantial changes in expenditures related to the home environment, from bills to home expenses. Notably, confidence intervals comprise a wider range of values for education fees and home expenses, but typical amounts for such expenditures are also much larger than for all other items as per Figure 2. In line with previous studies finding a positive MPC for non-durables among high-income families (Kueng, 2018), we find a positive albeit modest MPC for groceries, of around $1.9 \%$ per capita in the specification including time-varying controls $(p=.009)$.

For adult-assignable goods, finally, we find evidence of a positive MPC for adult clothing. Estimates suggest a propensity to spend around $5.7 \%$ of an extra dollar on adult clothing ( $p=.005$ in our second model specification). This implies that the reforms may have been associated with an annual reduction of around 57 AUD per each adult in spending for clothing, similar to the estimate for children's clothing. Estimates for alcohol suggest a negative MPC of around $-4.4 \%$ per dollar $(p=.106)$. This may suggest 
that the transfer, when provided, might have incentivised families to reduce spending on risky items such as alcohol. The same does not hold for cigarette spending, for which we estimate an MPC very close to 0 (MPC $=1.2 \%, p=.603$ when adding time-varying controls).

Evidence for labelling is thus mixed. The positive MPC for children's clothing suggests that, in the absence of reforms, higher-income families would have kept labelling part of the transfer for this child-assignable good. This is consistent with previous studies examining the same outcome, albeit typically for lower-income families (e.g. Kooreman, 2000; Gregg et al., 2006). Labelling does not seem to extend to education expenses (cf. Hener, 2017), however, where disparities in spending across families are more pronounced at the baseline (Figure 2). In addition, expenditures on adult-assignable goods, clothing in particular, also decrease for families affected by reforms and results point to a similar MPC for both adult and children's clothing. This stands in contrast with studies that highlighted how transfer recipients may substitute expenditures on adult clothing with those on child clothing (Kooreman, 2000). Differently from lowerincome families in previous studies (e.g. Raschke, 2016; Jones et al., 2019), families subject to policy changes do not seem to assign family cash transfers to essentials like bills or home maintenance, but do so, to an extent, with respect to groceries (Kueng, 2018). 


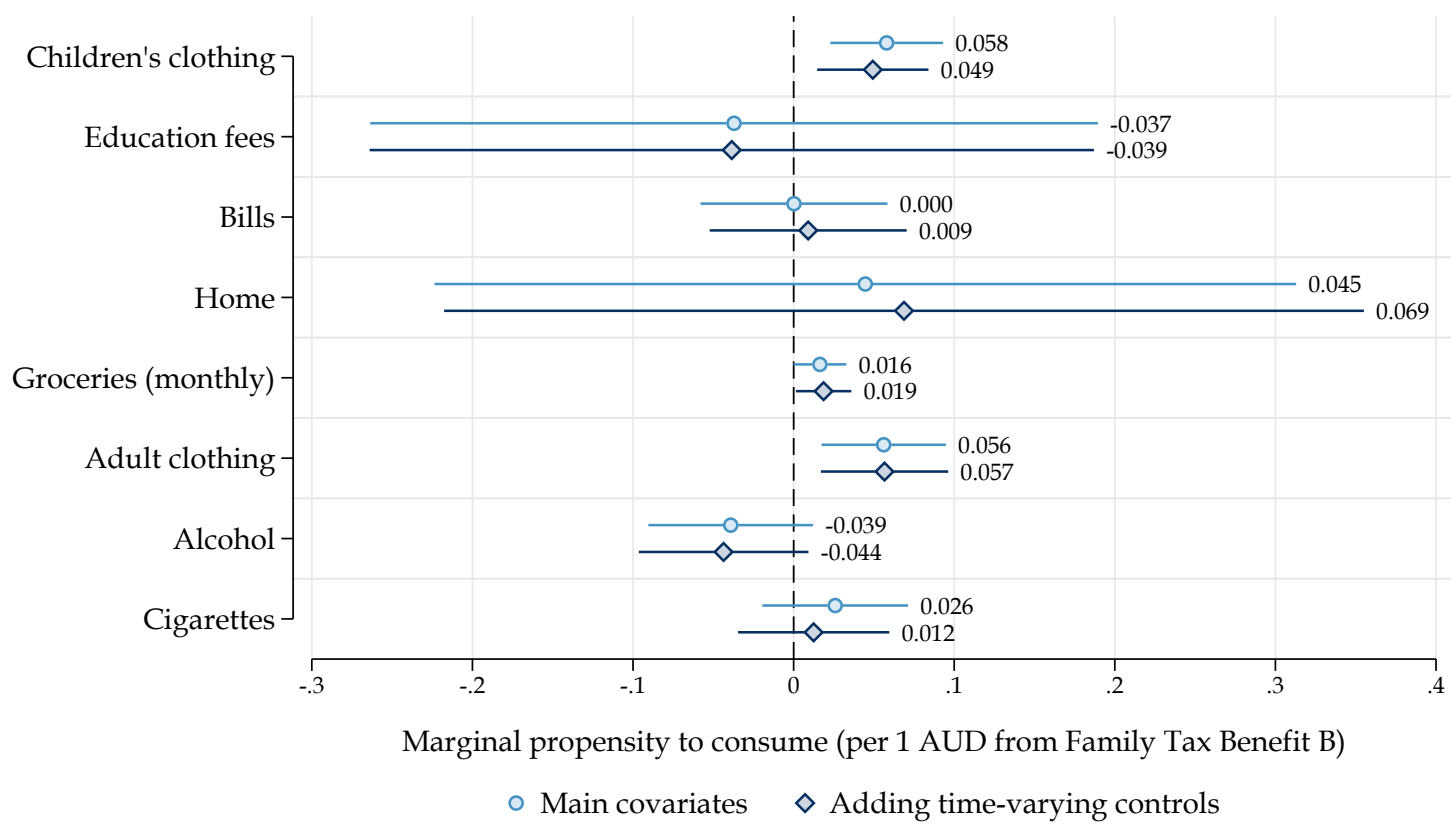

Figure 3: Point estimates and 95\% confidence intervals for IV estimates of the marginal propensity to consume one extra dollar from Family Tax Benefit Part B. Model specifications are presented in the main text (Equation 2). Standard errors are robust and clustered at the household level ( $N_{\text {observations }}=$ $32,541)$.

\subsection{Socioeconomic disparities in spending}

In Figure 4 we juxtapose IV estimates for higher-income families to MPCs obtained via Equation 3 for families in each income group. We find that families with relatively lower incomes seem to assign around .014 or $1.4 \%$ of the transfer to children's clothing $(p<.001)$. Such a value is around three times lower than the MPC we previously estimated for higher-income families (4.9\%). Considering a typical benefit amount of around 2,000 AUD for lower-income families, and 1,000 AUD for higher-income families (Figure 2), receiving the transfer may have led higher-income families to spend 49 AUD more per child, against 28 AUD among lower-income families. Prior to reforms, hence, FTB-B may have had some modest effects on inequality in expenditures for children's clothing. OLS interval estimates for higher-income families are, by and large, compatible with our IV estimates. As for point estimates, we find a 2.6\% MPC for families in the intermediate group $(p<.001)$ and an even larger one among families in top-income group $(10.9 \%, p<.001)$, suggesting that the latter might be the ones that used to earmark FTB-B for children's clothing the most. 
For education fees, we find a positive association between income from the family cash transfer and spending on children's education among lower-income families, equal to around $4.3 \%$ of a dollar $(p=.002)$. For higher-income families, IV estimates are much noisier but also compatible with OLS estimates. A tentative conclusion could be that families with relatively lower incomes label FTB-B for investments in their children's education $^{4}$, whereas higher-income families, with or without FTB-B, are already at the frontier of their spending for this item.

Perhaps surprisingly, we find that also families with lower incomes do not seem to earmark this cash transfer for bills $(.5 \%, p=.446)$ or home expenses $(.7 \%, p=.744)$. For groceries, lower-income households' $\mathrm{MPC}$ is at a much lower clip $(.3 \%, p=.117)$ than the one previously ascertained for higher-income households (1.9\%). A plausible explanation is that both lower- and higher-income families assign larger shares of income from sources other than FTB-B to essentials.

The starkest difference we find is for adult clothing. Compared to the 5.7\% MPC estimated for higher-income families (IV), we find no evidence of an association between income from the cash transfer and this expenditure item among lower-income families $(p=.600)$. Once again, the estimate for higher-income families seems to be driven by those in the top-income group, for whom OLS estimates point to a $8.8 \% \operatorname{MPC}(p=.01)$. More clearly than for higher-income families in the previous section, we find negative MPCs for "risky" items among families with lower incomes (for alcohol, $-2.2 \%, p<$ .001 ; for cigarettes, $-4.1 \%, p<.001)$.

The bottom line is that Family Tax Benefit Part B might have made small contributions to disparities in expenditures limited to children's and adult clothing, as well as groceries. As a result, reforms might have made small dents in the expenditure gaps for these items across the socioeconomic divide. Notably, the same does not hold for education fees. Overall, whilst more tentative, our estimates suggest clearer labelling effects among lower-income families (Kooreman, 2000; Gregg et al., 2006; Hener, 2017; Amorim, 2021; cf. Blow et al., 2012). OLS and IV estimates are generally compatible,

\footnotetext{
${ }^{4}$ When further broken down by income rank (Schneider et al., 2018), we do not detect a positive MPC for education fees among the least well-off households (below the 25th percentile of earnings), but only among households in the 26-75th percentile group, which arguably includes middle-class households (analyses are available upon request).
} 
and OLS results especially highlight the spending behaviour of families in the topincome group.

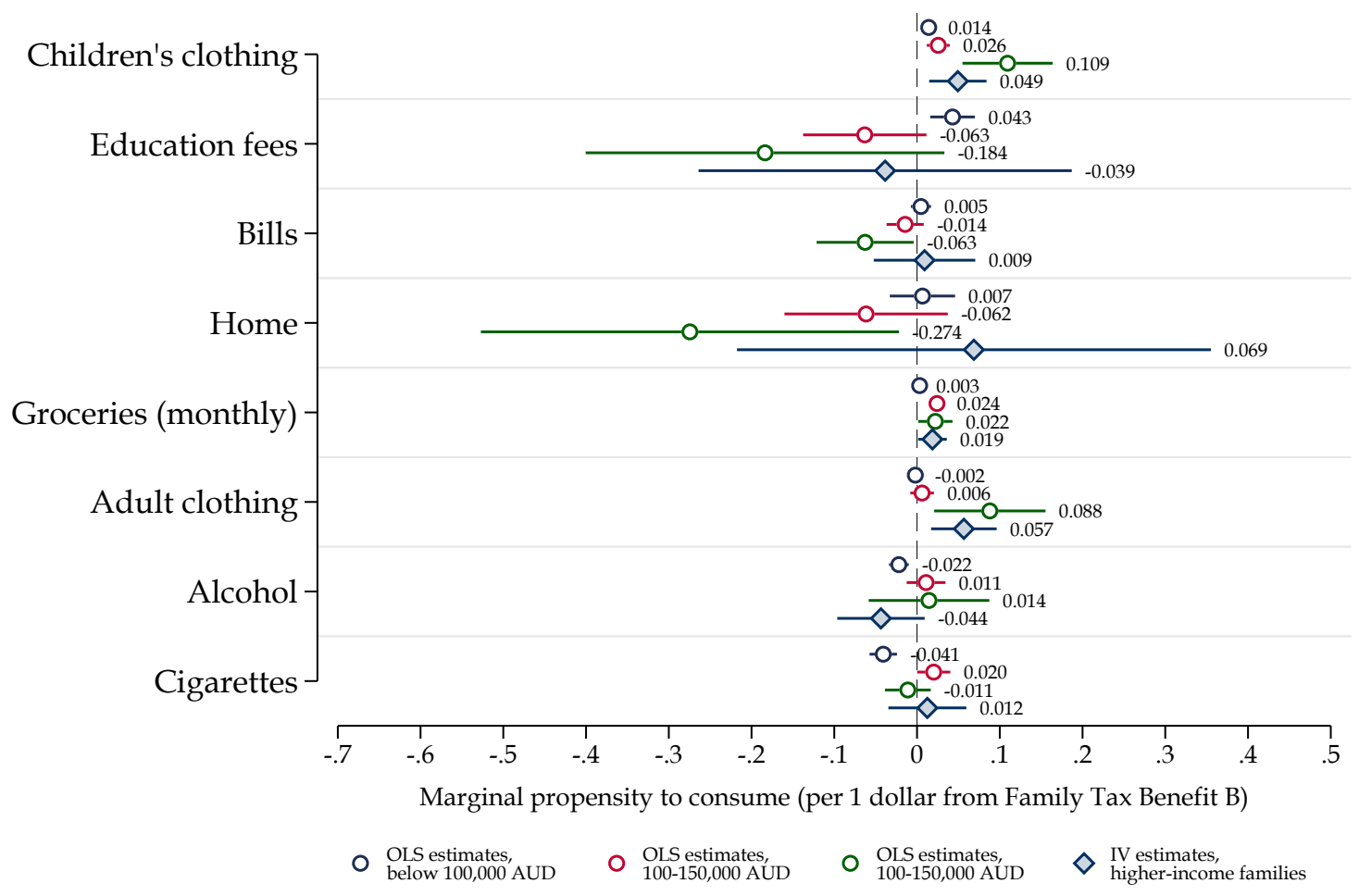

Figure 4: Point estimates and 95\% confidence intervals for OLS and IV estimates (with time-varying controls) of the marginal propensity to consume one extra dollar from Family Tax Benefit Part B. Model specifications are presented in the main text (Equation 3 and 2, respectively). Standard errors are robust and clustered at the household level. OLS estimates are split by income band ( $N_{\text {below } 100,000 \mathrm{AUD}}=$ $\left.24,328, N_{100-150,000 \mathrm{AUD}}=4,675, N_{\text {above } 150,000 \mathrm{AUD}}=2,782\right)$, whereas IV estimates rely on the whole sample $\left(N_{\text {observations }}=32,541\right)$.

\section{Robustness and sensitivity}

5.1. FTB-B reforms or something else? Labour supply adjustments and anticipation We now assess whether findings can be credibly attributed to FTB-B reforms and that we are thus recovering the MPC tied to a family cash transfer. A first common critique of research on family cash benefits is that families are affected not just by the cash transfer per se, but also via changes in parental labour supply and earnings spurred by the transfer (e.g. Heckman \& Mosso, 2014). Losing their FTB-B entitlements, families may want to put more effort into the labour market. Additional hours of work could re-orient some expenditures (e.g. adult clothing) and the extra earnings may counterbalance benefit loss and sustain current levels of expenditure. These changes would invalidate 
our test for labelling effects, as we assume the latter work solely through the withdrawal of FTB-B and, hence, through a shift in the composition of family income away from transfers. In other words, in the instrumental-variable setting, changes in labour supply and earnings could invalidate the exclusion restriction. If, vice versa, families reduce their labour supply so that their income does not cross the new thresholds for FTBB, this could violate the monotonicity assumption underlying instrumental-variable approaches. In our setting, monotonicity implies that all families are affected by the reform in the same way, i.e. that reforms led to the loss of FTB-B entitlements and do not encourage families to manipulate, say, their earnings to (re)gain FTB-B instead.

We thus re-estimate Equation 1 on total weekly working hours and total weekly earnings (2018-19 prices) per household. Results in the first column of Table 1A in the Appendix suggest that, among families in the top-income group, household labour supply might have increased by around 6.2 hours $(p=.003)$. Yet estimates greatly reduce and are no longer significant at conventional levels when including time-varying controls and their interaction with income-group dummies $(2 h, p=.247)$. Stepwise covariate inclusion (not shown) suggests that, by and large, apparent changes in labour supply over time are due to (likely exogenous) age dynamics among primary and secondary earners in top-income families. In line with findings for working hours, we find no evidence of changes in earnings among these families, nor do we detect any post-reform change in work hours and earnings for families in the intermediate income group. Findings lend credence, overall, to the idea that families did not need to adjust labour supply to recoup lost benefits, lending confidence to assumptions in the IV setting and to our interpretations concerning expenditure responses.

Another challenge comes from whether estimates can identify genuine reform effects on family expenditures, or rather reflect other changes in expenditures over time. Families could anticipate FTB-B reforms, by devoting more money to child-related goods before the benefit is withdrawn, or time dummies could be picking up changes in expenditures that were already ongoing prior to and unrelated to the reforms. We check for this by re-estimating Equation 1 directly on family expenditures, including interactions between income-group dummies, reform dummies, and additional "fake" or 
placebo reform dummies, i.e. time dummies that switch to 1 in the financial year before the first and second FTB-B reform, 2007-08 and 2014-15 respectively. Results are displayed in Figure 1A in the Appendix. All in all, estimates provide little evidence of changes in expenditures in the financial year preceding each reform. Similar results, omitted for the sake of brevity, also point to no anticipation in the two years prior each reform, thereby strengthening our claims on reform effects on family expenditures.

\subsection{Specification curves}

We also probed estimates to a number of choices pertaining to study design, to assess the sensitivity of our main findings. We present the rationale for each of these checks in Appendix 1A. In short, we alter both model specification, estimating linear and Poisson models with and without extensive covariates, and analytical samples, specially to account for other reforms in the period and for the fact that not all families, even when eligible for FTB, might have claimed payments.

Results are displayed in the form of specification curves in Appendix 1A. These checks, by and large, support the idea that higher-income families labelled FTB-B for children's clothing (Figure 2A). Statistically indistinguishable across specifications, point estimates for this MPC range between 3.2 and 10.8\%, with main estimates as per Figure 3 lying somewhat between these two values. Differently, though, estimates cannot support labelling for education fees. Once again, point estimates are statistically similar across specifications and close to 0 in most cases. Likewise, we cannot detect - and we often estimate rather precise nulls - for bills, home expenses, and groceries. As for adult-assignable goods, finally, the positive MPC found for adult clothing in Figure 3 is mostly detected in linear models. Poisson specifications suggest, instead, a much more conservative estimate with tight confidence bounds around 0. For risky items, a negative MPC for alcohol, ranging from 2.7 to $10.5 \%$, is similarly estimated across specifications, although it reaches conventional levels of statistical significance only in a handful of models. For cigarettes, we cannot reject the null across the board, similar to our main analyses.

Regardless of specification and sample choices, we thus find strong evidence of labelling among higher-income households, although only for children's clothing. 


\section{Discussion and conclusions}

We have examined whether and how higher-income households label family cash benefits for specific expenditures, focusing on reforms of Australia's largest transfer to families with children, Family Tax Benefit. Relatively overlooked, the study of how higherincome households use money from cash transfers can inform debates about both socioeconomic inequalities and policy. It has implications, first, for our understanding of the sources of inequality in parents' monetary investments in children, which in turn can contribute to children's disparate life chances. Second, questions on how families across the socioeconomic divide spend money from transfers can highlight trade-offs in policy design, between, for example, universal transfers and transfers that are efficient or equitable in helping (some) families with the economic costs of children.

We find four main results. First, higher-income families are likely to assign part of family cash benefits to children's clothing. Upon withdrawal of Family Tax Benefit Part B in Australia, spending on children's clothing decreased among higher-income families. Differently, we do not find evidence that higher-income families earmarked FTB-B for education fees. Second, higher-income families seem not to devote family cash benefits to bills, home repairs, and, as for groceries, a small and positive marginal propensity to consume is sensitive to choices regarding model specification and analytical sample. Third, families seem to assign part of the money not just to children's clothing, but to adult clothing too, although MPCs for this item are more sensible to model specification (linear v. Poisson). Finally, the more widespread provision of FTB-B before the reforms might have made small contributions to inequality in expenditures on clothing and groceries. At the same time, we find clearer labelling effects among lower- rather than higher-income families.

Hence, we do not find evidence of spending responses across the board among higherincome families, except for clothing items. One likely interpretation of our findings is that, while lower-income families might label family cash benefits more intensely, higher-income households might treat the extra money as a windfall (Kueng, 2018), spending part of it on extra items of clothing, including those for children. The null effect for children's education fees, on the other hand, might indicate that higher-income 
families are already at the frontier of their education spending - and a cash benefit that roughly equals $1 \%$ of their disposable income does not move the needle. The loss of such a small transfer might be easily absorbed by higher-income families, without prompting drastic changes such as transferring children to a more affordable school. If it did move the needle, we could have speculated that the extra cash was assigned to private tuition to compensate for poor educational performance - as predicted by theories of compensatory advantage (e.g. Huang, 2020) - or that it motivated parents to enrol their children in (even) more expensive schools at the margin. Spending on other enriching activities in tandem with formal education, such as extra-curricular activities, could also provide an alternative channel for labelling that we could not track via HILDA. Future research could shed light on these mechanisms, also by relying on more substantial policy changes.

The portion of the transfer assigned to children's clothing instead ranges from roughly 3 to $11 \%$ for higher-income families in this study, in line with the average MPC in studies on family cash transfers (Kooreman, 2000). The MPC for children's clothing among lower-income families is much lower instead, but FTB-B might be of secondary importance for lower-income households in Australia (Figure 1). Notably, studies that have looked at cash transfers that do not explicitly refer to 'families' or 'children', such as the Permanent Fund Dividend in Alaska, have found much smaller MPCs for the same item. Amorim (2021), for example, has found an MPC of around 0.3\% for children's clothing among both lower- and higher-income households receiving the dividend (see also Kueng, 2018). Family cash transfers might thus be effective in nudging families towards (some) child-related expenses. We can speculate that the few spending responses we observed among higher-income families have little impact on disparities among children. The assessment of such disparities was beyond the scope of this study, as it would have required data on child outcomes sensitive to parental monetary investments as well as a more in-depth look at the quality of such investments, not just their quantity. Research and policy could benefit from further investigations of spending (and saving) responses to cash transfers across the socioeconomic divide (e.g. Amorim, 2021), as well as what consequences these behaviours may have for child 
outcomes and the disparities therein (Duncan et al., 2017).

The first limitation of this study is that we can only assess spending responses to relatively modest benefit entitlements among higher-income families. Small amounts might indeed be treated as windfalls, but we cannot speak to how higher-income families would respond to larger transfers. In this sense, ours is a litmus test for labelling effects across selected spending categories: If detected in association with small transfers, labelling could be presumed to be more extensive under a more generous program. Second, we cannot couple our analyses of family spending with one of saving behaviour, lacking data on this margin. Even when summed up, the small MPCs we find might suggest that, barring assignment to expenditure items we did not observe, FTB-B might have contributed to household savings. Future studies could provide a more comprehensive picture incorporating savings, in line with recent research (Hener, 2017).

With these caveats in mind, our findings can inform the design of (family) cash benefit policies. A full cost-benefit analysis is beyond the remit of this paper, but what we add to previous literature is a focus on how higher-income families spend cash benefits. It is worth asking if cash transfers to higher-income families risk having unintended and perverse effects on inter-household inequality in expenditures. In this respect, we find that modest transfers to higher-income families seem to increase inequality in expenditures only for some goods (children's clothing, but not education fees) and by small amounts. Hence, universal transfers, often deemed desirable on several policy fronts (e.g. Atkinson, 2015; Shaefer et al., 2018), might not magnify inequality in parental expenditures, especially if higher-income families receive modest amounts. As for FTB in Australia, its means-tested features were reinforced, instead, by the reform process. It follows that the equalising promise of withdrawing entitlements from higher-income families is limited, at least with respect to the expenditures observed in this study ${ }^{5}$ In sum, our study is one of the first to provide an extensive test of expenditure re-

\footnotetext{
${ }^{5}$ One last limitation of our design is that estimated effects are inherently "local", in that they generalise to the treated by the reforms of interest (for a discussion, see Słoczyński, 2020). Well-off households affected by reforms claimed FTB-B in the first place. By the same token, these households might have been those more motivated to assign FTB-B for child-related spending. This positive correlation between reform exposure (compliance with the instrument) and treatment effects might lead to overestimation of spending responses in our setting (Heckman et al., 2006). Future research could examine contexts in which uptake of family cash benefits is (nearly) universal among the eligible.
} 
sponses to the receipt of family cash benefits in higher-income households. Additional evidence from other countries is needed (Raschke, 2016), as the design of family cash benefits remains topical. In 2013, the UK government effectively withdrew its main 'family-labelled' transfer, Child Benefit, from higher-income households, switching to a means-tested approach much in the same vein as the Australian one. In 2021, differently, countries like the US and Italy have introduced universal cash provisions for families with children. In the US, plans to make transfers permanent rather than a one-off have been halted, and public debate has also cast doubts on the use of such provisions among lower-income families. Similar questions have resurfaced in Australia, where an income management scheme has long restricted spending of cash benefits among disadvantaged communities - despite evidence of the program's ineffectiveness and negative externalities (e.g. Cobb-Clark et al., 2021). Our study finds, on the contrary, suggestive evidence that lower-income households invest family cash transfers in their children, in line with the bulk of previous literature. On top of that we have shown that, when inequality in family expenditures is a concern, only small trade-offs might exist when providing (modest) benefits to higher-income families too. 


\section{References}

Amorim, M. (2019). Are grandparents a blessing or a burden? Multigenerational coresidence and child-related spending. Social Science Research, 80, 132-144.

Amorim, M. (2021). Socioeconomic Disparities in Parental Spending after Universal Cash Transfers: The Case of the Alaska Dividend. Social Forces.

Andrews, I., Stock, J. H., \& Sun, L. (2019). Weak instruments in instrumental variables regression: Theory and practice. Annual Review of Economics, 11, 727-753.

Angrist, J. D., \& Pischke, J.-S. (2008). Mostly Harmless Econometrics. An Empiricist's Companion. Princeton University Press.

Antonides, G., De Groot, I. M., \& Van Raaij, W. F. (2011). Mental budgeting and the management of household finance. Journal of Economic Psychology, 32(4), 546-555.

Apps, P., \& Rees, R. (2010). Australian family tax reform and the targeting fallacy. Australian Economic Review, 43(2), 153-175.

Arthur, D. (2015). What counts as welfare spending? Accessed on 22 April 2021. Parliamentary Library Research Paper Series 2015-16, Parliament of Australia. Retrieved from https://www .aph.gov.au/About_Parliament/Parliamentary _Departments/Parliamentary_Library/pubs/rp/rp1516/WelfareSpend\#_ftn1

Atkinson, A. B. (2015). Inequality: What can be done? Harvard University Press.

Australian Bureau of Statistics. (2021). Personal income in Australia. ABS, Canberra. Retrieved 2022-03-01, from https://www.abs.gov.au/statistics/labour/ earnings-and-work-hours/personal-income-australia/latest-release

Benhassine, N., Devoto, F., Duflo, E., Dupas, P., \& Pouliquen, V. (2015). Turning a shove into a nudge? A "labeled cash transfer" for education. American Economic Journal: Economic Policy, 7(3), 86-125.

Bennett, F. (2013). Researching within-household distribution: Overview, developments, debates, and methodological challenges. Journal of Marriage and Family, 75(3), 582-597.

Blow, L., Walker, I., \& Zhu, Y. (2012). Who benefits from child benefit? Economic Inquiry, 50(1), 153-170.

Bodovski, K., \& Farkas, G. (2008). "Concerted cultivation" and unequal achievement in elementary school. Social Science Research, 37(3), 903-919. 
Cheadle, J. E., \& Amato, P. R. (2011). A quantitative assessment of Lareau's qualitative conclusions about class, race, and parenting. Journal of Family Issues, 32 (5), 679-706.

Cobb-Clark, D. A., Kettlewell, N., Schurer, S., \& Silburn, S. (2021). The Effect of Quarantining Welfare on School Attendance in Indigenous Communities. Journal of Human Resources, 1218-9909R2.

de Gendre, A., Schurer, S., \& Zhang, A. (2021). Two Decades of Welfare Reforms in Australia: How Did They Affect Single Mothers and Their Children? IZA Discussion Paper No. 14752.

Department of Families, Housing, Community Services, and Indigenous Affairs. (2011). Annual Report 2010-11. DSS, Canberra.

Department of Human Services. (2009). A guide to Australian Government payments. Accessed on 22 April 2021. DHS, Canberra. Retrieved from https://www.servicesaustralia.gov.au/organisations/about-us/corporate -publications-and-resources/guide-australian-government-payments/ historical-versions-guide-australian-government-payments

Department of Human Services. (2016). A guide to Australian Government payments. Accessed on 22 April 2021. DHS, Canberra. Retrieved from https://www.servicesaustralia.gov.au/organisations/about-us/corporate -publications-and-resources/guide-australian-government-payments/ historical-versions-guide-australian-government-payments

Department of Human Services. (2019). A guide to Australian Government payments. Accessed on 21 April 2021. DHS, Canberra. Retrieved from https://www.servicesaustralia.gov.au/organisations/about-us/corporate -publications-and-resources/guide-australian-government-payments

Department of Social Services. (2020). Annual Report 2019-20. DSS, Canberra.

Department of Social Services and Melbourne Institute of Applied Economic and Social Research. (2021). The Household, Income and Labour Dynamics in Australia (HILDA) Survey, GENERAL RELEASE 19 (Waves 1-19). ADA Dataverse. Retrieved from http://dx.doi.org/10.26193/3QRFMZ

Duflo, E. (2001). Schooling and labor market consequences of school construction in Indonesia: Evidence from an unusual policy experiment. American Economic Review, 91(4), 795-813.

Duncan, G. J., Magnuson, K., \& Votruba-Drzal, E. (2017). Moving beyond correlations in assessing the consequences of poverty. Annual Review of Psychology, 68, 413-434. 
Edmonds, E. (2002). Reconsidering the labeling effect for child benefits: Evidence from a transition economy. Economics Letters, 76(3), 303-309.

Gornick, J. C., \& Smeeding, T. M. (2018). Redistributional policy in rich countries: Institutions and impacts in nonelderly households. Annual Review of Sociology, 44, 441-468.

Gregg, P., Waldfogel, J., \& Washbrook, E. (2006). Family expenditures post-welfare reform in the UK: are low-income families starting to catch up? Labour Economics, 13(6), 721-746.

Harding, A., Vu, Q. N., Tanton, R., \& Vidyattama, Y. (2009). Improving work incentives and incomes for parents: the national and geographic impact of liberalising the family tax benefit income test. Economic Record, 85, S48-S58.

Hastings, O. P., \& Schneider, D. (2021). Family structure and inequalities in parents' financial investments in children. Journal of Marriage and Family, 83(3), 717-736.

Heckman, J. J., \& Mosso, S. (2014). The economics of human development and social mobility. Annu. Rev. Econ., 6(1), 689-733.

Heckman, J. J., Urzua, S., \& Vytlacil, E. (2006). Understanding instrumental variables in models with essential heterogeneity. The Review of Economics and Statistics, 88(3), 389-432.

Hener, T. (2017). Effects of labeled child benefits on family savings. Review of Economics of the Household, 15(3), 759-777.

Huang, M.-H. (2020). Compensatory advantage and the use of out-of-school-time tutorials: A cross-national study. Research in Social Stratification and Mobility, 66, 100472.

Hudson, S., Hull, P., \& Liebersohn, J. (2017). Interpreting instrumented difference-indifferences. MIT mimeo. Retrieved from http://www.mit.edu/ hull/DDIV.pdf

Jackson, M. I., \& Schneider, D. (2021). Public Investments and Class Gaps in Parents' Developmental Expenditures. American Sociological Review, 87(1), 105-142.

Jones, L. E., Milligan, K., \& Stabile, M. (2019). Child cash benefits and family expenditures: Evidence from the National Child Benefit. Canadian Journal of Economics / Revue canadienne d'économique, 52(4), 1433-1463.

Ko, W., \& Moffitt, R. (2022). Take-up of Social Benefits. NBER Working Paper w30148.

Kooreman, P. (2000). The labeling effect of a child benefit system. American Economic Review, 90(3), 571-583. 
Kornrich, S., \& Furstenberg, F. (2013). Investing in children: Changes in parental spending on children, 1972-2007. Demography, 50(1), 1-23.

Kueng, L. (2018). Excess sensitivity of high-income consumers. The Quarterly Journal of Economics, 133(4), 1693-1751.

Lareau, A. (2003). Unequal Childhoods: Class, Race, and Family Life. University of California Press.

Lenhart, O. (2019). The effects of income on health: new evidence from the Earned Income Tax Credit. Review of Economics of the Household, 17(2), 377-410.

Lye, J., \& Hirschberg, J. (2017). Secondary school fee inflation: an analysis of private high schools in Victoria, Australia. Education Economics, 25(5), 482-500.

Lynch, J., Meunier, A., Pilkington, R., \& Schurer, S. (2019). Baby Bonuses and Early-Life Health Outcomes: Using Regression Discontinuity to Evaluate the Causal Impact of an Unconditional Cash Transfer. IZA Discussion Paper No. 12230.

Lyssiotou, P. (2018). Gender bias in the spending of child benefits: Evidence from a natural policy reform. International Tax and Public Finance, 25(4), 1029-1070.

Mood, C. (2006). Take-Up Down Under: Hits and misses of means-tested benefits in Australia. European Sociological Review, 22(4), 443-458.

Olea, J. L. M., \& Pflueger, C. (2013). A robust test for weak instruments. Journal of Business \& Economic Statistics, 31(3), 358-369.

Raschke, C. (2016). The impact of the German child benefit on household expenditures and consumption. German Economic Review, 17(4), 438-477.

Ribar, D. C. (2017). Welfare and children's well-being. Australian Economic Review, $50(3), 348-355$.

Schneider, D., Hastings, O. P., \& LaBriola, J. (2018). Income inequality and class divides in parental investments. American Sociological Review, 83(3), 475-507.

Shaefer, H. L., Collyer, S., Duncan, G., Edin, K., Garfinkel, I., Harris, D., ... Yoshikawa, H. (2018). A universal child allowance: a plan to reduce poverty and income instability among children in the United States. RSF: The Russell Sage Foundation Journal of the Social Sciences, 4(2), 22-42.

Słoczyński, T. (2020). When Should We (Not) Interpret Linear IV Estimands as LATE? arXiv preprint arXiv:2011.06695. 
Summerfield, M., Garrard, B., Hahn, M., Jin, Y., Kamath, R., Macalalad, N., .. Wooden, M. (2020). HILDA User Manual-Release 19. Melbourne Institute of Applied Economic and Social Research University of Melbourne.

Sun, C. (2010). HILDA Expenditure Imputation. HILDA Project Technical Paper Seires No. 1/10, March 2010.

Thaler, R. H. (1985). Mental accounting and consumer choice. Marketing Science, 4(3), 199-214.

Thaler, R. H. (1999). Mental accounting matters. Journal of Behavioral Decision Making, 12(3), 183-206.

Wilkins, R. (2014). Derived Income Variables in the HILDA Survey Data: The HILDA Survey 'Income Model'. HILDA Project Technical Paper Seires No. 1/14, March 2014.

Zelizer, V. A. (2017). The social meaning of money: Pin money, paychecks, poor relief, and other currencies. Princeton University Press. 


\section{Do high-income families 'label' family cash benefits? Evidence on family expenditures from Australia Appendix}

Table 1A: Reform effects on labour supply and earnings (Equation 1).

\begin{tabular}{lcccc}
\hline & \multicolumn{3}{c}{ Working hours } & \multicolumn{2}{c}{ Earnings } \\
\cline { 2 - 5 } & Coef. & Coef. & Coef. & Coef. \\
& $(\mathrm{SE})$ & $(\mathrm{SE})$ & $(\mathrm{SE})$ & $(\mathrm{SE})$ \\
\hline Income group $=$ Above 150,000 AUD $\times$ After 2008-09 & $6.2^{* * *}$ & 2 & 189 & 87 \\
& $(2.1)$ & $(1.8)$ & $(189.9)$ & $(194.3)$ \\
Income group = 100-150,000 AUD $\times$ After 2015-16 & 0.1 & 0.5 & 27.1 & 44.4 \\
& $(1.1)$ & $(0.7)$ & $(48.2)$ & $(42.4)$ \\
\hline Other income-group/period dummies and their interaction & Yes & Yes & Yes & Yes \\
Main covariates & Yes & Yes & Yes & Yes \\
Adding time-varying controls & No & Yes & No & Yes \\
\hline
\end{tabular}

Note: ${ }^{* * *} p<.001$. Sets of covariates are detailed in the main text. Standard errors are robust to heteroskedasticity and are clustered at the household level $\left(N_{\text {observations }}=32,541\right)$.

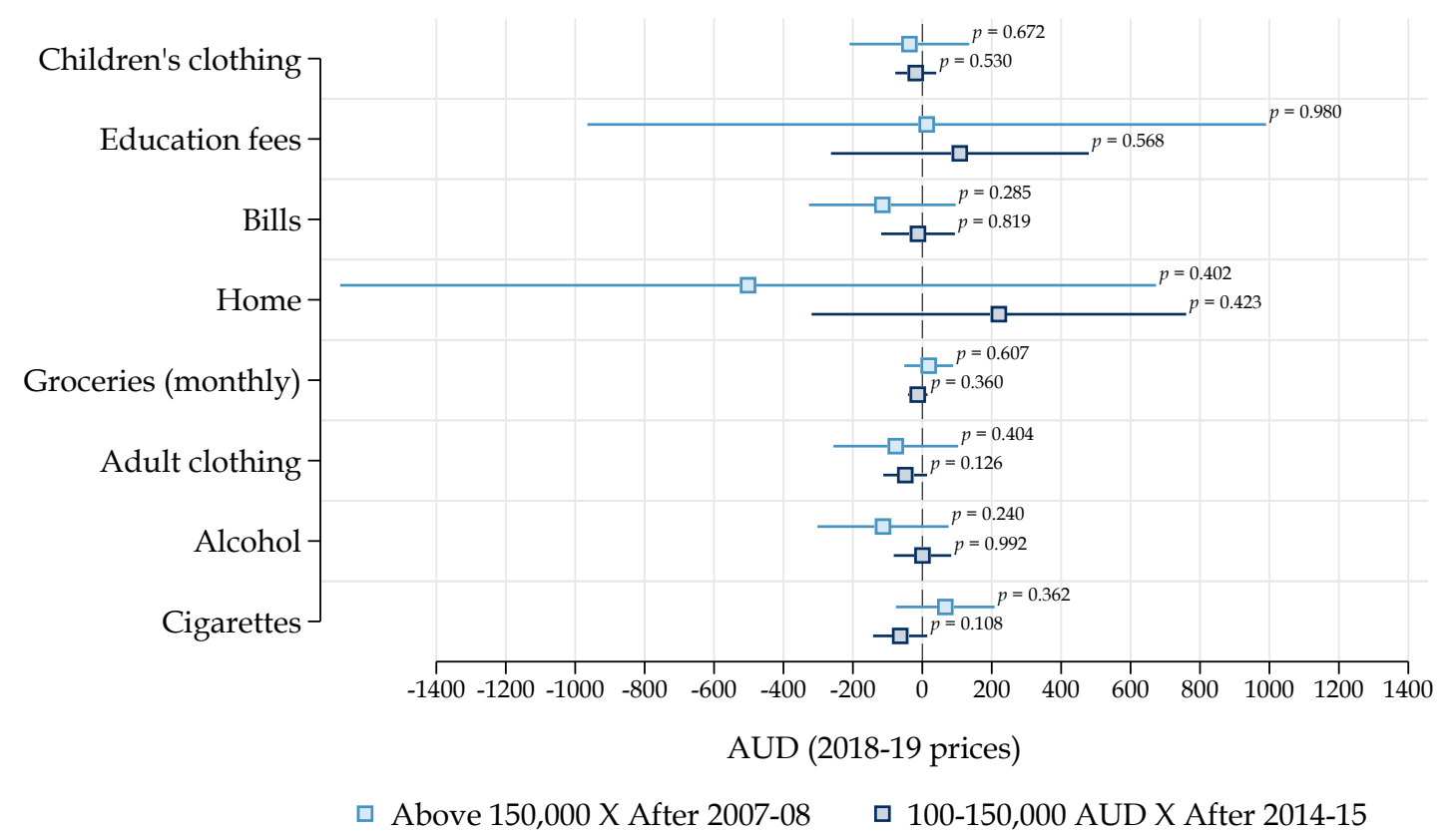

Figure 1A: Point estimates and 95\% confidence intervals for the effects of income-group by period interactions. Displayed periods are one year prior to the one in which each income group was affected by real FTB-B reforms. Models are estimated via OLS, are saturated in income-group-by-period interactions (4 periods: after 2007-08, 2008-09, 2014-15, 2015-16), and include the most extensive set of controls (see text). Standard errors are robust to heteroskedasticity and are clustered at the household level $\left(N_{\text {observations }}=32,541\right)$. 


\section{A. Specification curves in detail}

We examine alternative specifications for Equations 1 and 2. In our main analyses, we followed prior research by using a linear model. Expenditures are non-negative outcomes, often with a large number of 0 s (e.g. for cigarettes), and a skewed and overdispersed distribution. We thus probe estimates using a generalised linear model with a log link function (Poisson), which might be more suitable in such a setting. In line with our main analyses, we estimate linear and Poisson models with both a more parsimonious set of covariates as well as an extensive one, including time-varying controls and their interaction with income-group dummies.

Similar considerations go into selecting alternative samples. First, we re-estimated models by excluding households with any dependent children aged 0-4, possibly subject to changes to other family cash benefits. Child Care Benefit was withdrawn from July 2008 from high-income households (Department of Human Services, 2009). The Australian Baby Bonus was introduced in 2004 (3,000 AUD lump sum for each birth on or after 1 July 2004), made more generous in July 2006 (4,000 AUD) and July 2008 (5,000 AUD), became means-tested as of 2009, and was then abolished in March 2014 (Lynch et al., 2019). Finally, National Paid Parental Leave was introduced in 2011. All these reforms mainly affected families with children of pre-school age.

Second, our main analyses have been based on a sample of households with children in the widest age range covered by FTB in the period. Such age range was subject to reform, though, as described in the Background section. We repeated analyses using the most restrictive age range instead, one that granted eligibility throughout the whole period, namely children aged 0-13 for two-parent families and 0-17 for single-parent ones.

In our paper, we have relied on the HILDA's Income Model (Wilkins, 2014), which assigns FTB amounts to each household based on its characteristics and benefit criteria in each period. However, the uptake of FTB might be incomplete (see footnote 1 in the main text). Higher-income families, in particular, might not go through the trouble of applying for FTB given the more meagre benefit amounts. For a third alternative sample, we use data from HILDA's core survey on self-reported FTB receipt, whereby respondents report if they have been receiving FTB in the past year. We restricted the sample to households who, if assigned a non-zero FTB-B amount by the Income Model, also report any FTB receipt in HILDA.

Fourth, we consider other reforms that may have touched on FTB and/or its use. A supplement to FTB Part A (worth up to 720-730 AUD per child per year, Department of Human Services, 2016) was withdrawn from families with a total income above 80,000, starting in 2016-17. We thus re-estimated our model by excluding families in which the incomes of the primary or sole earner totalled between 80 and 100,000 AUD. The comparison group is thus limited to households with incomes below 80,000 AUD. 
Similarly, we also ran analyses on a sample that excludes Australia's Northern Territory (NT). Starting in 2007, the NT government rolled out a new income management scheme, first targeted exclusively at families in indigenous communities. The program required half of a household's total welfare payments to be quarantined for spending on food, housing, and household goods. Cobb-Clark and colleagues (2021) provide a review of extant evidence and a comprehensive evaluation of the policy change. For our purposes, there is little evidence that the reform altered spending patterns, as most targeted households already devoted more than half of their incomes to priority needs. Nevertheless, since the reform also applied to payments from Family Tax Benefit, we ran a specification that excludes NT respondents from the sample.

Finally, we acknowledge that single mothers were affected by more policy changes, including to FTB itself (e.g. de Gendre et al., 2021), and that their spending patterns might differ from those of two-parent families (e.g., Hastings \& Schneider, 2021). We thus dropped single-parent households from the sample for one of the specification checks.

Combining 4 alternative specifications and 7 different samples, we obtain 28 estimates for each expenditure item. These are displayed in the following specification curves. Results are summarised in the main text. 


\section{Children's clothing}

- Main spec. $\quad-\quad 95 \% \mathrm{CI}$
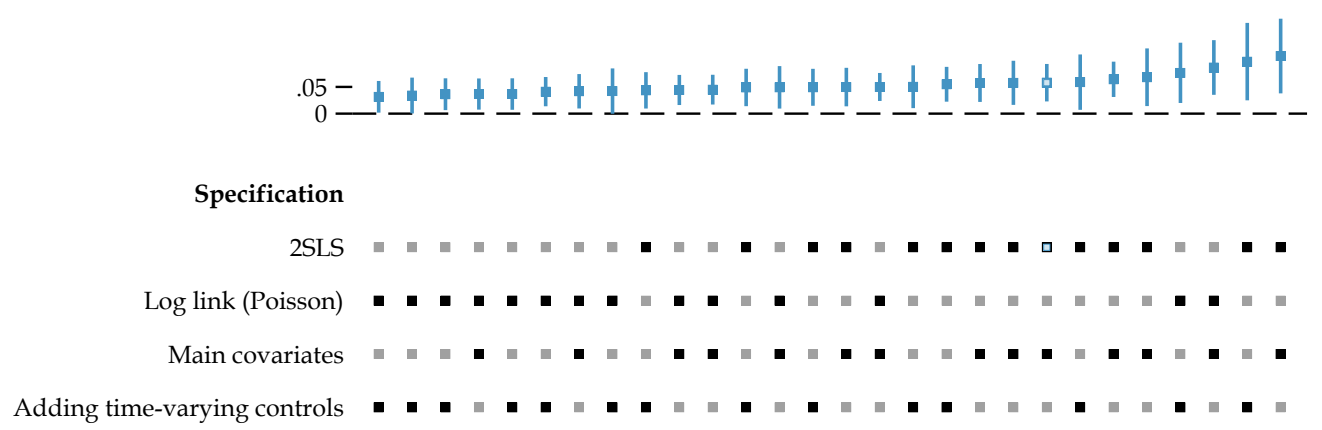

Sample

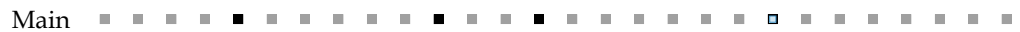

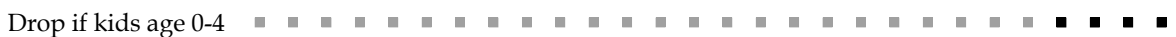

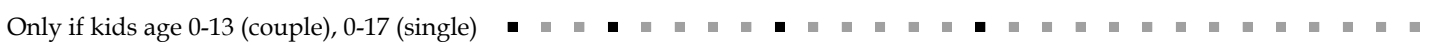

Drop if estimated FTB $\neq$ self-reported FTB ㅁ -

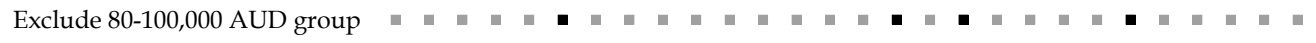

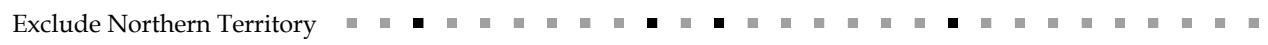

Exclude single parents ㅁ |

Note: $p \leq .05$ in 27 out of 28 estimates, point estimates range from .032 to .108 .

Figure 2A: Point estimates and 95\% confidence intervals for the marginal propensity to consume (MPC) 1 dollar out of Family Tax Benefit Part B among higher-income households. 


\section{Education fees}

- Main spec. $\quad$ - $95 \% \mathrm{CI}$

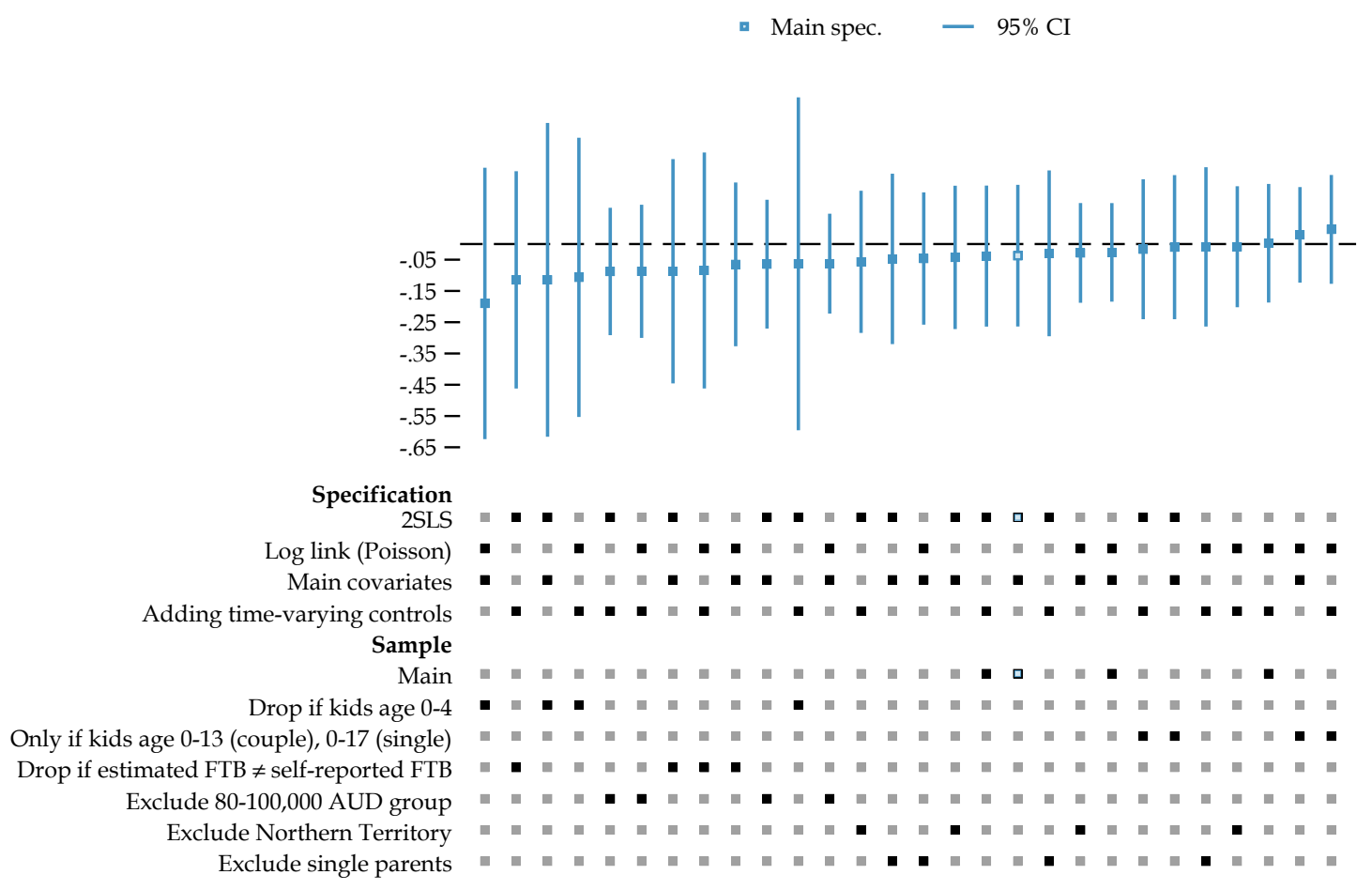

Note: $p \leq .05$ in 0 out of 28 estimates, point estimates range from -.19 to .047 .

Figure 3A: Point estimates and 95\% confidence intervals for the marginal propensity to consume (MPC) 1 dollar out of Family Tax Benefit Part B among higher-income households. 


\section{Bills}

- Main spec. $\quad-\quad 95 \% \mathrm{CI}$
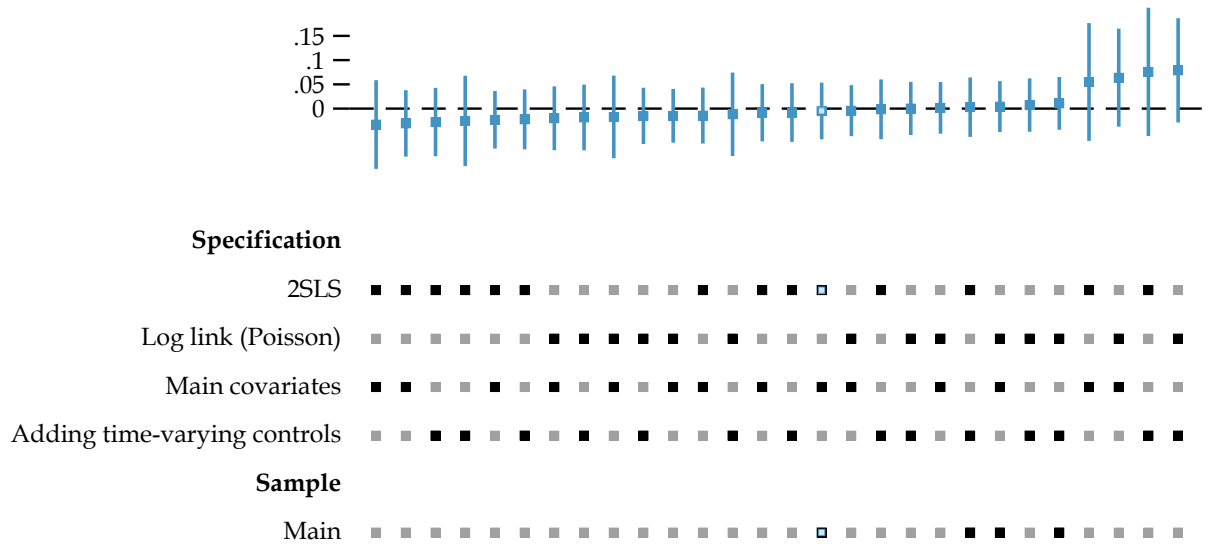

Drop if kids age $0-4$ 口

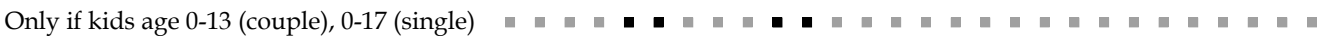

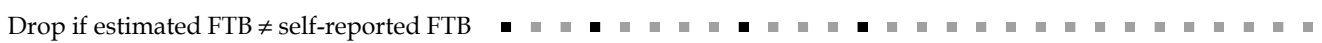

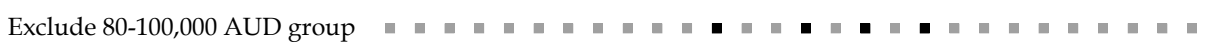

Exclude Northern Territory $\square$ घ

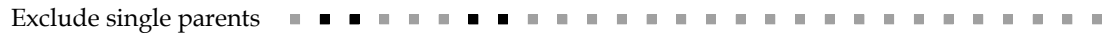

Note: $p \leq .05$ in 0 out of 28 estimates, point estimates range from -.033 to .079 .

Figure 4A: Point estimates and 95\% confidence intervals for the marginal propensity to consume (MPC) 1 dollar out of Family Tax Benefit Part B among higher-income households. 


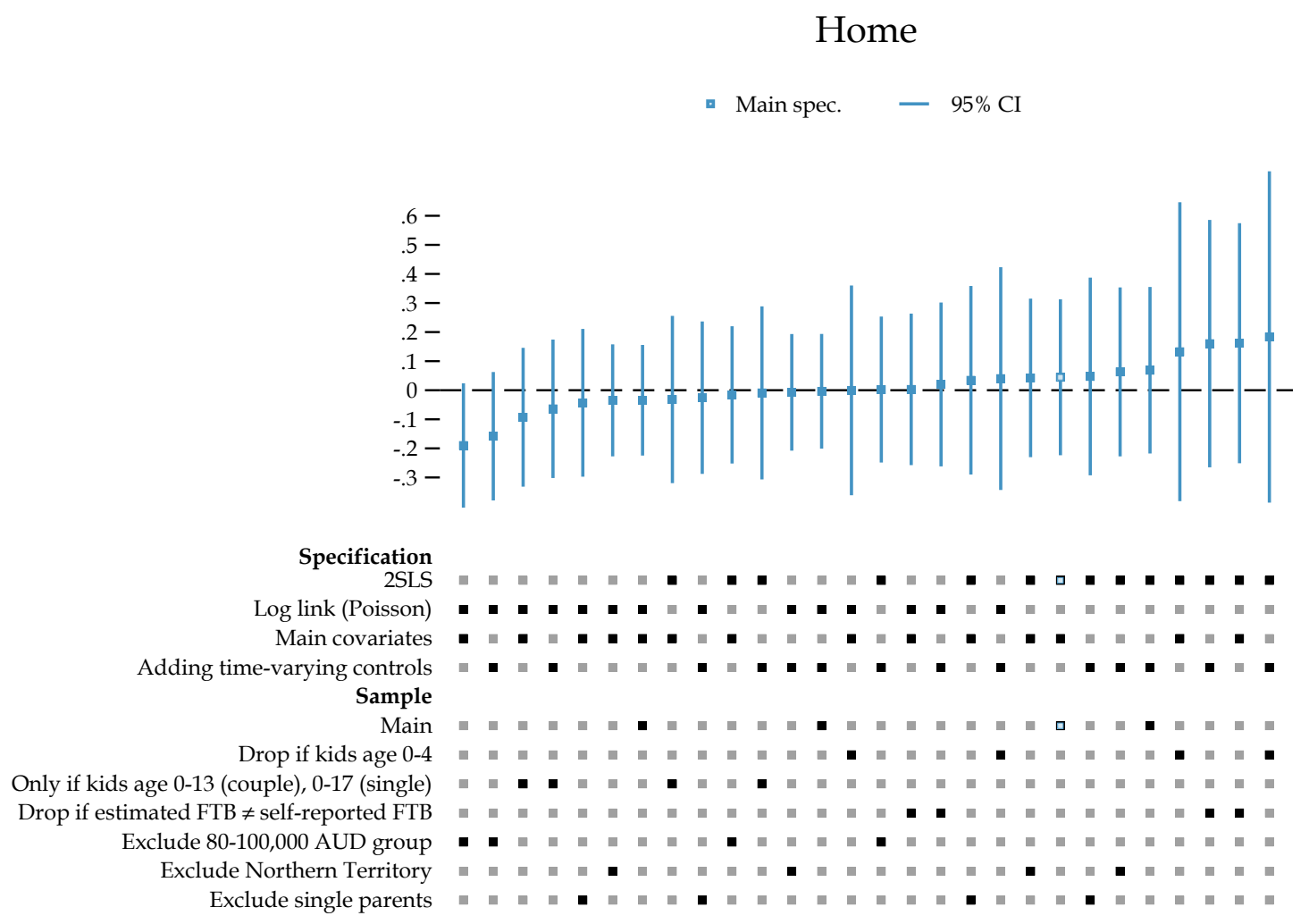

Note: $p \leq .05$ in 0 out of 28 estimates, point estimates range from -.19 to .183 .

Figure 5A: Point estimates and 95\% confidence intervals for the marginal propensity to consume (MPC) 1 dollar out of Family Tax Benefit Part B among higher-income households. 


\section{Groceries (monthly)}

- Main spec. $\quad-\quad 95 \% \mathrm{CI}$

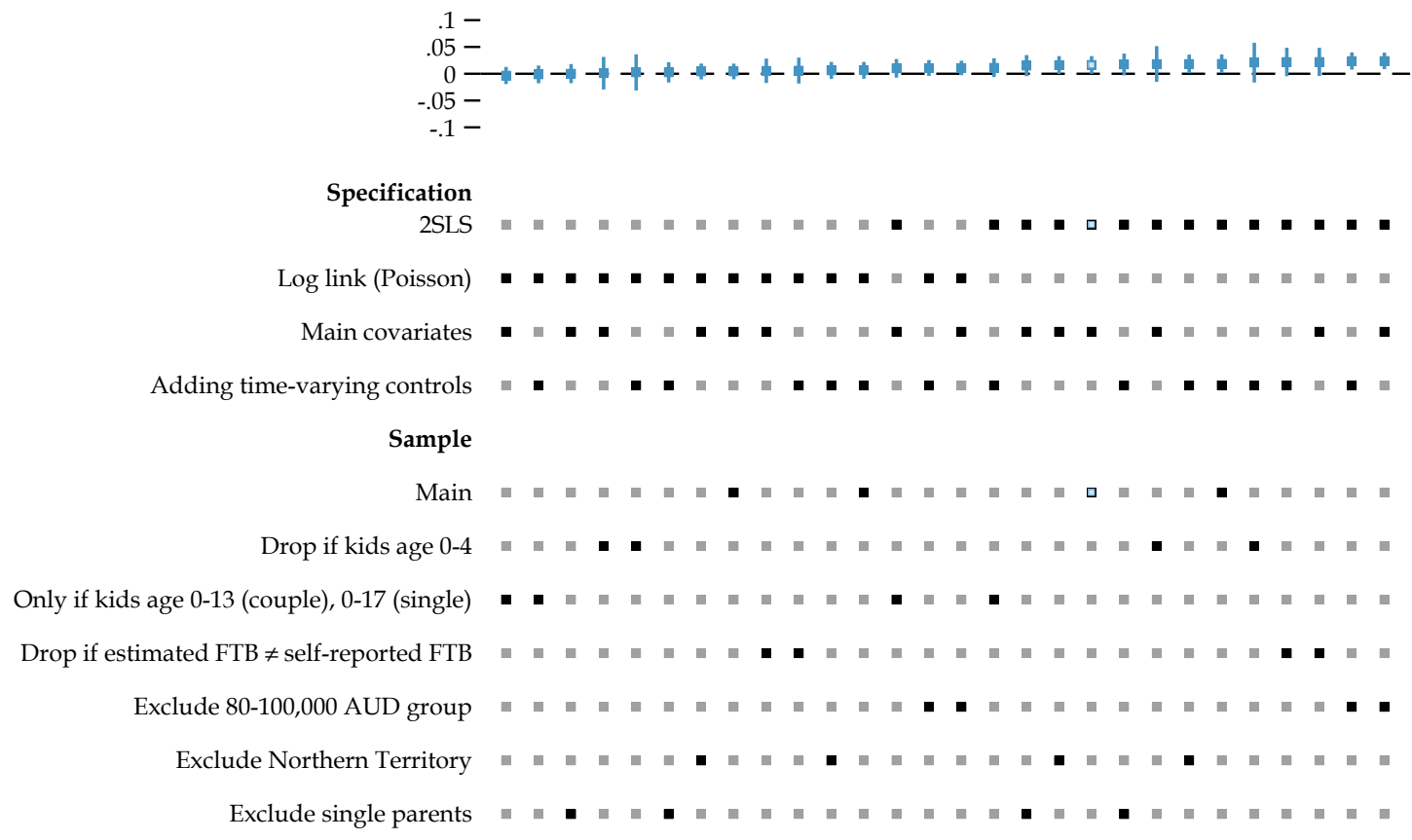

Note: $p \leq .05$ in 4 out of 28 estimates, point estimates range from -.003 to .024 .

Figure 6A: Point estimates and 95\% confidence intervals for the marginal propensity to consume (MPC) 1 dollar out of Family Tax Benefit Part B among higher-income households. 


\section{Adult clothing}

- Main spec. $\quad-\quad 95 \% \mathrm{CI}$

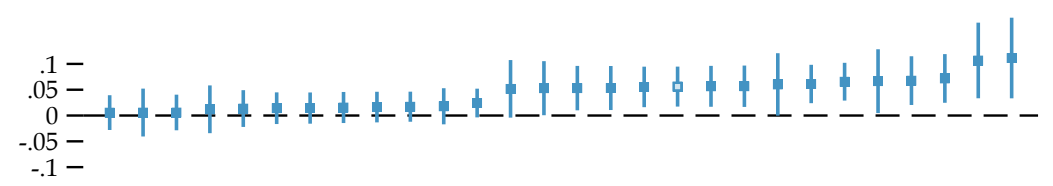

Specification

2SLS

Log link (Poisson)

Main covariates

Adding time-varying controls
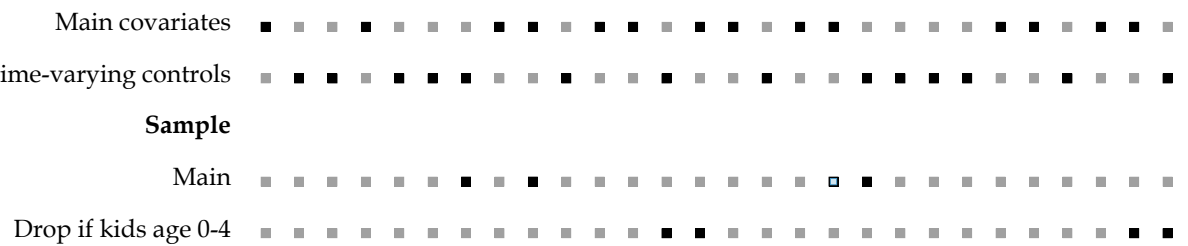

Only if kids age 0-13 (couple), 0-17 (single)

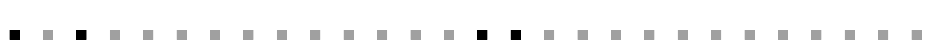

Drop if estimated FTB $\neq$ self-reported FTB

Exclude 80-100,000 AUD group

Exclude Northern Territory

Exclude single parents

Note: $p \leq .05$ in 14 out of 28 estimates, point estimates range from .006 to .111 .

Figure 7A: Point estimates and 95\% confidence intervals for the marginal propensity to consume (MPC) 1 dollar out of Family Tax Benefit Part B among higher-income households. 


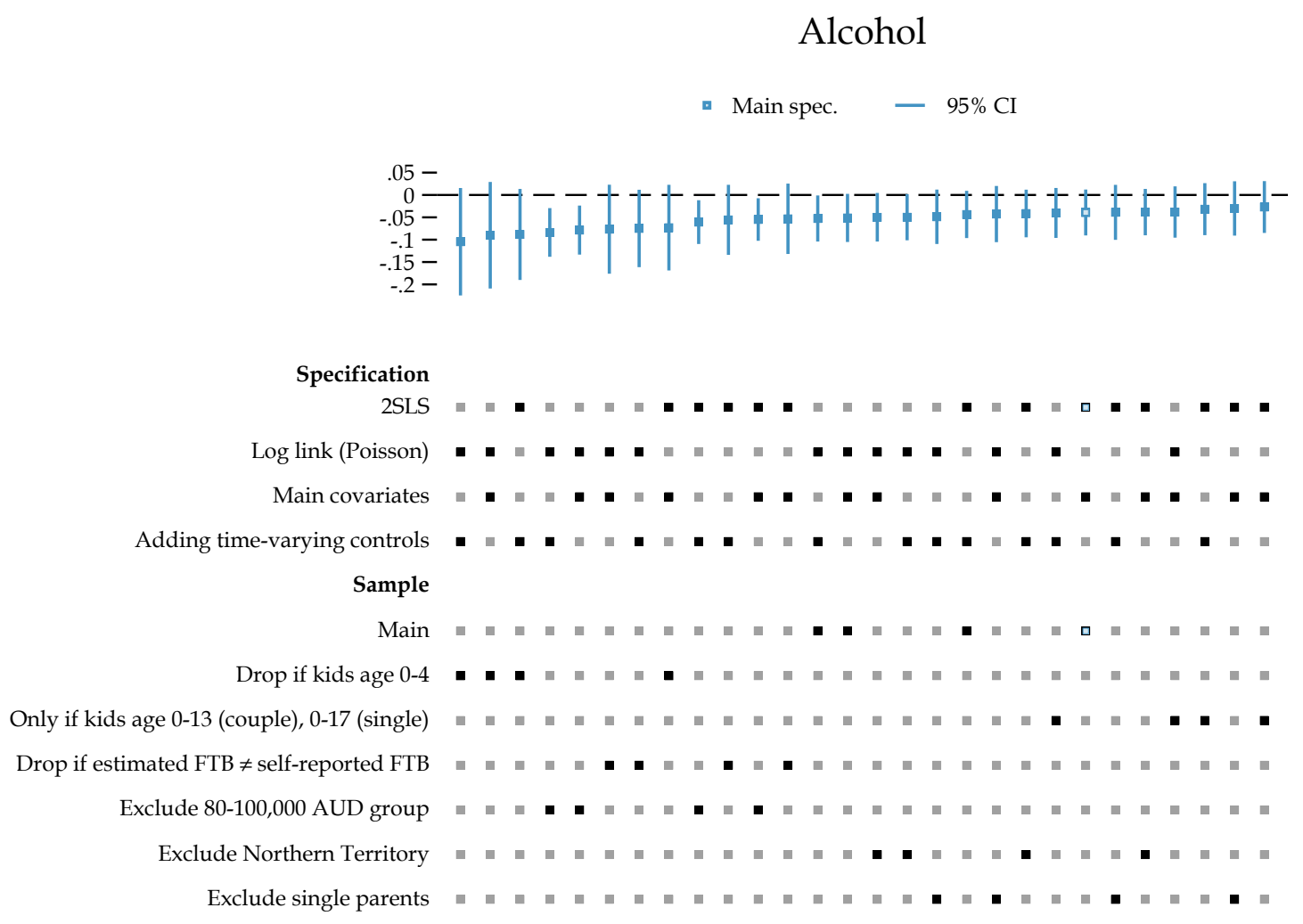

Note: $p \leq .05$ in 5 out of 28 estimates, point estimates range from -.105 to -.027.

Figure 8A: Point estimates and 95\% confidence intervals for the marginal propensity to consume (MPC) 1 dollar out of Family Tax Benefit Part B among higher-income households. 


\section{Cigarettes}

Main spec. $\quad-\quad 95 \% \mathrm{CI}$

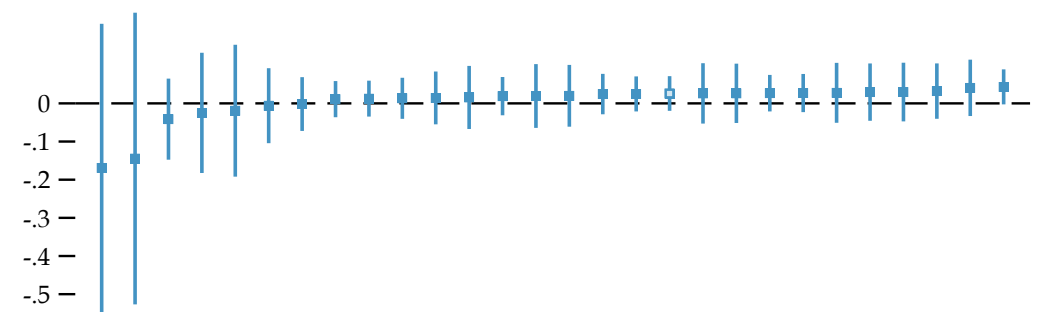

Specification

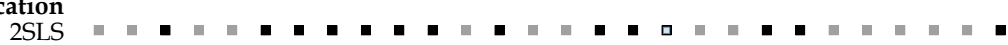

$\log \operatorname{link}($ Poisson) | | | | | | | | | | | | | | | | | | | | | | | | | | -

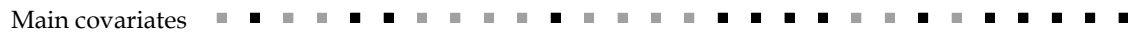

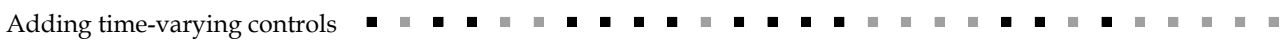

Sample

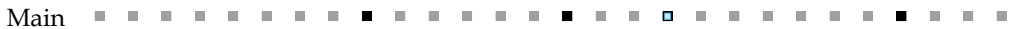

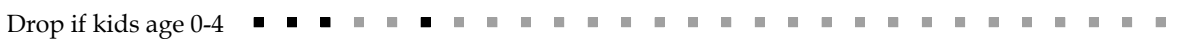

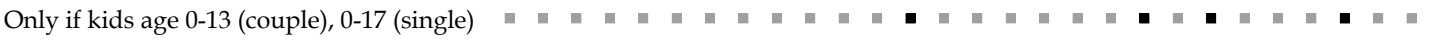

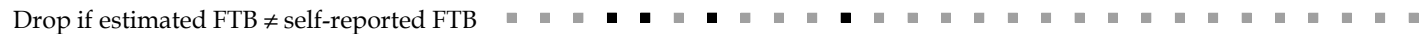

Exclude 80-100,000 AUD group = -

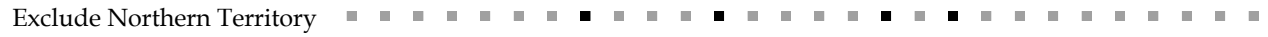

Exclude single parents | -

Note: $p \leq .05$ in 0 out of 28 estimates, point estimates range from -.169 to .043 .

Figure 9A: Point estimates and 95\% confidence intervals for the marginal propensity to consume (MPC) 1 dollar out of Family Tax Benefit Part B among higher-income households. 